\title{
Einleitung des Bandherausgebers
}

Dieser Band umfasst alle bekannten Manuskripte Schleiermachers zu seinen Vorlesungen über die Ästhetik, die er 1819, 1825 und 1832/33 an der Berliner Universität gehalten hat, sowie eine Auswahl von Vorlesungsnachschriften. Bei Schleiermachers Manuskripten handelt es sich neben seinem Kollegheft, das er für alle drei Kollegien verwendet hat, um vorbereitende Notizen, Exzerpte und Aphorismen. $\mathrm{Zu}$ jedem der drei Kollegien wird eine der insgesamt sieben überlieferten Nachschriften wiedergegeben: für das Kolleg 1819 die durch Odebrecht überlieferte Nachschrift von Friedrich Blubme, für das Kolleg 1825 die Nachschrift von Moritz Bindemann und für das Kolleg 1832/33 diejenige von Alexander Schweizer. Der Anhang enthält darüber hinaus Dokumente über die Ästhetik aus Schleiermachers Hand, die den Vorlesungen nicht direkt zugeordnet werden können, darunter vorbereitende Notizen zur dritten Akademieabhandlung „Über den Umfang des Begriffs der Kunst in Bezug auf die Theorie derselben“, ergänzend zu Band 11 der I. Abteilung der KGA („Akademievorträge"). Der Band enthält unveröffentlichte und bereits veröffentlichte Manuskripte und ist die bislang umfassendste Ausgabe der Ästhetikvorlesungen Schleiermachers.

\section{Historische Einfübrung}

\section{Vorgeschichte}

Wie aus biographischen Dokumenten hervorgeht, hegte Schleiermacher Zeit seines Lebens ein besonderes Interesse für die Kunst, namentlich für Literatur und Musik. Bereits in seiner Zeit im Pädagogium Niesky und im Seminarium von Barby (1783-1787) las er nicht nur antike Klassiker wie Homer, Hesiod oder Pindar, sondern auch Goethes „Werther" oder Wielands Gedichte. ${ }^{1}$ Seine Tageskalender

1 Vgl. Kurt Nowak: Schleiermacher. Leben, Werk und Wirkung, Göttingen 2001, S. 24-28. 
belegen Schleiermachers Fortführung dieses literarischen Interesses in seiner Berliner Zeit: Zwischen 1808 und 1810 las er erneut Homers Epen, aber auch Ovid und Vergil sowie Lessings „Minna von Barnhelm" und Goethes „Wahlverwandtschaften".2 Außerdem sang Schleiermacher ab 1808 in der Berliner Singakademie unter Zelter Tenor, besuchte die Singakademie mitunter mehrmals wöchentlich und darüber hinaus bis in die 1830er Jahre verschiedene Berliner Opern- und Konzertaufführungen. ${ }^{3}$ Seine rege Anteilnahme am musikalischen Leben seiner Zeit, zu der er auch durch seine kirchlichen Tätigkeiten motiviert war, belegen nicht nur die Musikalien in seiner Bibliothek, sondern auch sein Briefwechsel: Schleiermachers Verbindung mit dem Komponisten Johann Friedrich Reichhardt und dessen Familie in Giebichenstein bei Halle, der er in der "Weihnachtsfeier" ein Denkmal setzte, führte zu einer Brieffreundschaft mit Reichardts Tochter Luise, die ebenfalls komponierte und später einen Chor leitete; dieser Austausch dürfte Schleiermacher Einblicke in die gegenwärtigen Entwicklungen der Instrumental-und Vokalmusik vermittelt haben. ${ }^{4}$ Auch mit seiner Briefpartnerin, der Musikliebhaberin Charlotte Cummerow, tauschte er sich über musikalische Themen wie über die Bedeutung Beethovens in seiner Zeit aus. ${ }^{5}$

Seine ersten theoretischen Kenntnisse von der Ästhetik dürfte Schleiermacher während seines Studiums (1787-1789) von seinem philosophischen Lehrer und Förderer an der Universität Halle, Jo-

2 Vgl. Wolfgang Virmond: „Schleiermachers Lektüre nach Auskunft seiner Tagebücher", in: Günter Meckenstock (Hg.) in Verb. mit Joachim Ringleben: Schleiermacher und die wissenschaftliche Kultur des Christentums, Berlin / New York 1991, S. 71-99, hier: 74-76.

3 Vgl. Schleiermacher: Tageskalender 1809, erarbeitet von Wolfgang Virmond unter Mitarbeit von Holden Kelm, in: schleiermacher digital / Schleiermachers Tageskalender 1808-1834, hg.v. Elisabeth Blumrich, Christiane Hackel, Wolfgang Virmond, Berlin-Brandenburgische Akademie der Wissenschaften, Berlin. URL: https://schleiermacher-digital.de/tageskalender/index.xql (abgerufen 23.06.2020).

4 Vgl. den Briefwechsel zwischen Schleiermacher und Luise Reichardt 1808-1810, KGA V/10 und KGA V/11, hg.v. Simon Gerber und Sarah Schmidt, Berlin/Boston 2015, der auch online verfügbar ist: schleiermacher digital / Briefe, Berlin-Brandenburgische Akademie der Wissenschaften, Berlin. URL: https://schleiermacherdigital.delindex.xql (abgerufen 23.06.2020). Günter Meckenstock: Schleiermachers Bibliothek nach den Angaben des Rauchschen Auktionskatalogs und der Hauptbücher des Verlages G. Reimer, KGA I/15, Anhang, Berlin / New York 2005.

5 Am 20. Januar 1808 schrieb Charlotte Cummerow an Schleiermacher: „Beethoven ist gewiß (darüber bin ich mit Ihnen einig) der verdienstvollste Künstler unsrer heutigen Zeit, aber er ist auch der schwerste" (Brief 2613, KGA V/10, S. 27). 
hann August Eberhard, erworben haben. ${ }^{6}$ Eberhard, der die Schulphilosophie von Leibniz und Christian Wolff gegen den aufkommenden Kantischen Kritizismus verteidigte, verfasste selbst eine "Theorie der schönen Wissenschaften“ (1786), später ein „Handbuch der Aesthetik" (1803-1805), und betreute u.a. eine Neuausgabe von Baumgartens „Metaphysik“ (1783)..$^{7}$ Schleiermachers frübe Beschäftigung mit ästhetischen Fragestellungen lässt sich in seinem Aufsatz „Über das Naive" (1789) beobachten. ${ }^{8}$ Darin untersucht er Mendelssohns Schrift „Über das Erhabene und Naive in den schönen Wissenschaften" $(1771)^{9}$ näher und erörtert mit dem Naiven, Erhabenen und Lächerlichen ästhetische Kategorien, die in der Ästhetik der Spätaufklärung und Empfindsamkeit diskutiert wurden. Schleiermacher kritisiert Mendelssohns Begriff des Naiven dabei vor allem aus ethischer Perspektive als unzulänglich, weil er die äußerlichen Bewegungen als auch die charakterlichen Eigenheiten eines Menschen nicht hinreichend zu erfassen erlaube. Auch in seiner Schrift „Über die Freiheit“, die um 1790 entstand, behandelt Schleiermacher die Ästhetik nur am Rande. ${ }^{10}$ Die kurze Untersuchung des ästhetischen Urteils darin betrifft nicht etwa das Geschmacksurteil im Kantischen Sinne, sondern die Frage, inwiefern die Behandlung des Moralischen mit der des Ästhetischen in Beziehung gesetzt werden könne. ${ }^{11}$

In der Abhandlung „Über den Stil“ (1790/91) erörtert Schleiermacher die Art und Weise der sprachlichen Mitteilung von Empfindungen und Gedanken und insofern eine durchaus ästhetische Thematik. ${ }^{12}$ Er geht davon aus, dass eine unmittelbare Mitteilung von

${ }^{6}$ Bei Eberhard besuchte Schleiermacher u. a. ein Kolleg über die Geschichte der Philosophie, über Metaphysik und über philosophische Moral, in dem er sich mit der „Nikomachischen Ethik" von Aristoteles auseinandersetzte. Vgl. Nowak: Schleiermacher (Anm. 1), S. 35.

7 Johann August Eberhard: Theorie der schönen Wissenschaften, Halle 1786 (2. Auflage). Ders.: Handbuch der Aesthetik, für gebildete Leser aus allen Ständen. In Briefen, 4 Bde., Halle 1803-1805 (2. Auflage 1807-1820). Alexander Gottlieb Baumgarten: Metaphysik, hg.v. J. A. Eberhard und Georg Meier, 9. Auflage, Halle 1783.

8 Schleiermacher: Über das Naive, KGA I/1, hg. v. Günter Meckenstock, Berlin / New York 1984, S. 177-187.

9 Moses Mendelssohn: Philosophische Schriften, 2. Auflage, 2. Theil, Berlin 1771, S. 153-240.

10 Schleiermacher: Über die Freiheit, KGA I/1, S. 217-356; vgl. Günter Meckenstock: "Historische Einfübrung", ebd., S. LVIII.

11 Schleiermacher: Über die Freiheit, KGA I/1, S. 258-262.

12 Schleiermacher: Über den Stil, KGA I/1, S. 365-390. Schleiermacher exzerpierte für diese Schrift offenbar Beispiele aus Johann Christoph Adelungs „Ueber den Deutschen Styl" (Berlin 1785), für das er wohl eine Rezension plante. Wolfgang Virmond: Schleiermachers Schlobittener Vorträge „Über den Stil“ von 1791 in un- 
Empfindungen oder Gedanken nicht möglich sei, weshalb eine solche Mitteilung nur indirekt mit Hilfe von Zeichen erfolgen könne, bei denen er natürliche, wesentliche und willkürliche unterscheidet. Entsprechend der Annahme, dass sich dieser Zeichen auch alle Künste und Wissenschaften bedienten, unterscheidet Schleiermacher drei verschiedene Ausdrucks- und Stilformen in den Künsten: 1. Insofern Gebärden und Töne zu den natürlichen Zeichen gehören, sei die Kunst ihres Ausdrucks der mimische oder musikalische Stil, 2. Malerei und Bildnerei seien Ausdrucksformen wesentlicher Zeichen, die auf sinnliche Eindrücke zurückgingen, weshalb es auch einen besonderen Stil in den bildenden Künsten gebe, 3. Poesie und Rhetorik stellten schließlich die Kunst des Ausdrucks von Vorstellungen durch die willkürlichen Zeichen der Sprache dar. ${ }^{13}$ Diese Dreiteilung hat Schleiermacher offenbar in kritischem Anschluss an Eberhards „Theorie der schönen Wissenschaften" (1786) entwickelt, der darin die schönen Wissenschaften und Künste aufgrund eines ähnlichen dreigliedrigen Zeichenmodells einteilt. ${ }^{14}$ Obwobl Schleiermacher in seinen Ästhetikvorlesungen ab 1819 die Rhetorik nicht als eine eigene Kunstform behandelt, bildet Eberhards semiotischer Ansatz offenbar eine Art Blaupause für seine Einteilung der Künste in die drei Abteilungen: begleitende (Mimik und Musik), bildende (Architektur, Skulptur, Malerei) und redende Künste (Poesie). ${ }^{15}$

Von einer ausführlichen Auseinandersetzung mit der ästhetischen Theorie seiner Zeit finden sich in Schleiermachers Frühschriften insge-

bekannten Nachschriften, in: Synthesis Philosophica (Nr. 23), Bd. 12, H. 1, Zagreb 1997, S. 7-38.

13 Schleiermacher: Über den Stil, KGA I/1, S. 365.

14 Eberhard: Theorie der schönen Wissenschaften (Anm. 7), S. 6-7. Ders.: Theorie der schönen Künste und Wissenschaften, Halle 1790 (3. Auflage), S. 6-7, 16. Eberhard antwortete mit dieser Konzeption auf eine Debatte, die von Moses Mendelssohn angeregt wurde, der der Behandlung der Kunst in Baumgartens Ästhetik eine Verengung auf die Poesie und die Rhetorik vorhielt und demgegenüber ein semiotisches Einteilungsschema vorschlug, das alle schönen Künste und Wissenschaften umfasst. Vgl. Norman Kasper: „Ontologischer Sensualismus als Restitution der sinnlichen Erkenntnis und dessen Kritik. Zweierlei Begründung der seelischen Empfindung durch die Sichtbarkeit (Eberhard und A. W. Schlegel)", in: Hans-Joachim Kertscher / Ernst Stöckmann (Hg.): Ein Antipode Kants? Johann August Eberhard im Spannungsfeld von spätaufklärerischer Philosophie und Theologie, Berlin / New York 2012, S. 225-250, hier: 226-231.

15 Eine ähnliche Einteilung der Künste findet sich auch in Eberhards „Handbuch der Aesthetik": 1. die „practischen" Künste Musik und Orchestik, 2. die "bildenden" Künste Baukunst, Bildhauerkunst und Malerei sowie 3. die „redenden“ Künste. Vgl. J. A. Eberhard (Hg.): Handbuch der Aesthetik, für gebildete Leser aus allen Ständen in Briefen, 3. Th., Halle 1804, S. 63. 
samt nur vereinzelte Hinweise. So kritisiert er in „Über den Wert des Lebens" (1793) die zeitgenössische Kunsttheorie in einer Passage scharf, weil deren Unterfangen, das „ästhetische Gefühl" allein durch seine Übereinstimmung mit einer Verstandesregel einschätzen zu wollen, zu abstrakt sei: „Hätten wir erst die absolute Theorie des aesthetischen Gefühls welches wahrscheinlich unmöglich ist, dann möchte eine solche Anmaßung Statt finden, aber dann würden wir auch nothwendig einen ganz anderen Blik in diese Dinge haben. Jezt ist jedes System einer Kunst oder irgend einer Anwendung des Schönheitsgefübls nur bypothetisch und berubt immer auf Voraussezungen und Beobachtungen über das angenehme und schikliche bei welchen gar keine Allgemeinheit möglich ist. " ${ }^{16}$ Das individuelle "Schönheitsgefübl" und der „ästhetische Genuß" blieben daher letztlich unabhängig von der Beschaffenheit und Ausbildung einer allgemeinen Theorie des Schönen, womit Schleiermacher der Ästhetik der Spätaufklärung eine unreflektierte Kluft zwischen Sinnlichkeit und Verstand attestiert. Zu dieser Zeit hatte sich Schleiermacher zwar bereits mit Kants „Kritik der praktischen Vernunft“ auseinandergesetzt, dessen „Kritik der Urteilskraft" (1790) dürfte er aber erst später rezipiert haben - briefliche Zeugnisse deuten darauf hin, dass er sie erst spät im Jahr 1792 während seiner Schlobittener Zeit zur Verfügung hatte. ${ }^{17}$

16 Schleiermacher: Über den Wert des Lebens, KGA I/1, S. 391-471, hier: 451-452.

17 Sein Hallenser Studienfreund Duisburg informierte Schleiermacher in einem Brief vom 4. Dezember 1792 aus Danzig: „Auch sind noch Bücher für Dich von Troschel angelangt [...]. Es sind: Kants Kritik der Urtheilskraft - Nößelts theologische Bücherkunde - und Fülleborns Beyträge [zur Geschichte der Philosophie]. " (Brief 204, KGA V/1, hg.v. Andreas Arndt und Wolfgang Virmond, Berlin / New York 1985, S. 274) Ferdinand Troschel war ein Verlagsbuchhändler in Danzig, von dem Duisburg offenbar Bücher für Schleiermacher besorgte, die er diesem dann nach Schlobitten übermittelte. Er kannte zu dieser Zeit wohl auch bereits Kants „Beobachtungen über das Gefühl des Schönen und Erhabenen" (1771), auf die ibn Johannes Baptist von Albertini in einem Brief vom 12. Mai 1787 hinwies (Brief Nr. 68, KGA V/1, S. 78). Die zweite Auflage der „Kritik der Urteilskraft" von 1793 besaß Schleiermacher dann auch in seiner Bibliothek (SB: 1021). - Schleiermachers frühe Kant-Rezeption ist in der Forschung in Bezug auf Kants praktische Philosophie bereits herausgestellt worden, in Bezug auf Kants Ästhetik finden sich jedoch nur vereinzelte Arbeiten. Vgl. Günter Meckenstock: Deterministische Ethik und kritische Theologie. Die Auseinandersetzung des frühen Schleiermacher mit Kant und Spinoza 1789-1794, Berlin / New York 1988. Peter Grove: Deutungen des Subjekts: Schleiermachers Philosophie der Religion, Berlin / New York 2004, S. 29. Denis Thouard: „Schleiermacher et Kant: les modalités de l'assentiment", in: Claude Piché (Hg.): Années 1781-1801. Kant, Critique de la raison pure. Vingt ans de réception, Paris 2002, S. 183-193. 
Diese frühen verstreuten Gedanken und Aussagen Schleiermachers zur Ästhetik erweitern und verändern sich nachhaltig in seiner Berliner Zeit zwischen 1796 und 1802. Nachdem Friedrich Schlegel 1797 von Jena nach Berlin gezogen war und Schleiermacher ibn in der „Mittwochsgesellschaft" von Ignaz Aurelius Feßler kennen gelernt hatte, entstand zwischen beiden in kürzester Zeit eine konstruktive Freundschaft, die durch die Differenzen über die als gemeinsames Projekt geplante Platon-Übersetzung jedoch strapaziert wurde und nach Schlegels Konversion zum Katholizismus 1808 weiter abkühlte. ${ }^{18}$ Die Entwicklung ibres philosophischen und ästhetischen Denkens verlief in dieser Phase in einem wechselseitigen „symphilosophischen" Austausch, wovon Schleiermachers Fragmente und Rezensionen für das „Athenaeum “ zeugen. ${ }^{19}$ In seinen „Vertrauten Briefen“ (1800) begegnete Schleiermacher den zablreichen Kritikern von Friedrich Schlegels Roman „Lucinde“ (1799) mit deutlichen Worten und verteidigte die frühromantischen Überzeugungen von der Lebendigkeit der Poesie, dem Enthusiasmus für die Vernunft und die Geselligkeit. ${ }^{20}$ Dass Schleiermacher zu dieser Zeit selbst Pläne hegte, es seinen dichtenden Freunden gleich zu tun, belegen die poetischen Versuche, die er vor allem in seiner Stolper Zeit unternahm. Diese Pläne gediehen jedoch nicht über einige Gedichte, einen Romanentwurf und später regelmäßig verfasster Charaden hinaus - die poetischen Qualitäten seiner frühromantischen Schriften einmal ausgenommen. ${ }^{21}$ Auch begann Schleiermacher in Stolp neben seinen geistlichen Pflichten als Pfarrer mit der Platon-Übersetzung, in deren Zuge er sich auch mit den verstreuten Aussagen Platons über das Schöne und die Kunst auseinandersetzte, wovon dann etwa seine „Einleitungen“ $z u$ den Über-

$18 \mathrm{Vgl}$. Andreas Arndt: "Eine literarische Ehe. Schleiermachers Wohngemeinschaft mit Friedrich Schlegel", in: ders.: Schleiermacher als Philosoph, Berlin/Boston 2013, S. 31-41.

19 Die Brüder Friedrich und August Wilhelm Schlegel gaben zwischen 1798 und 1800 in Berlin die Zeitschrift „Athenaeum" heraus. Im 2. Stück des 1. Bandes von 1798 finden sich Fragmente von F. Schlegel, A. W. Schlegel, Friedrich von Hardenberg (Novalis) und Schleiermacher, in denen keine Autorschaft ausgewiesen wird. Die nachweislich von Schleiermacher stammenden (wohl 31) Fragmente sind inzwischen abgedruckt in: KGA I/2, hg. v. Günter Meckenstock, Berlin / New York 1988, S. 141-156. Schleiermacher rezensierte in diesem Rahmen etwa auch Kants „Anthropologie in pragmatischer Hinsicht" (1798).

$20 \mathrm{Vgl}$. Schleiermacher: Vertraute Briefe über Friedrich Schlegels Lucinde, KGA I/3, hg.v. Günter Meckenstock, Berlin / New York 1988, S. 139-216.

21 Vgl. Hermann Patsch: Alle Menschen sind Künstler. Friedrich Schleiermachers poetische Versuche (Schleiermacher-Archiv 2), Berlin / New York 1986. 
setzungen der Dialoge „Phaidros“, „Politeia“ und „Symposion“ zeugen. $^{22}$

Schleiermachers erstes, anonym in Berlin veröffentlichtes Buch „Über die Religion. Reden an die Gebildeten unter ibren Verächtern“ (1799) ist ohne seine Beteiligung am frübromantischen Diskurs kaum denkbar. Aus den "Reden" erwächst die bis in die Gegenwart gefübrte Diskussion über die „Kunstreligion“ - ein Neologismus Schleiermachers, den er jedoch nur in der Erstauflage verwendete. ${ }^{23}$ Die Art und Weise, wie Schleiermacher darin Kunst und Religion als zwei „,befreundete Seelen" mit "innerer Verwandtschaft" und gleichwertige Quellen der "Anschaunng des Unendlichen" engführt, zeitigt bis beute den Vorwurf, Schleiermacher ästhetisiere die Religion. ${ }^{24}$ Schleiermacher legt in den „Reden" die gestaltbildende Kraft der Kunst zwar durchaus als eine Art Vervollkommnung der im Gefühl wurzelnden Religiosität dar, bestreitet aber, dass die Kunst die Religion gänzlich ersetzen könnte, weil sich vielmehr beide „befreundete Seelen“ wechselseitig bedingten. Die Hoffnung auf eine Verschmelzung von Religion und Kunst bewegt sich im Rahmen von Schleiermachers Kritik der abstrakten Religionsauffassung der Spätaufklärung und der Religionspädagogik seiner Zeit.

Dass die frühromantische Ästhetik in mancher Hinsicht wegbereitend war für das, was in den Ästhetiken der klassischen deutschen Philosophie nach Kant systematisch ausformuliert wurde, liegt auf der Hand; nicht zuletzt war es das Verwandtschaftsverhältnis von Kunst und Religion, das auch in Schellings und Hegels Vorlesungen über die Philosophie der Kunst bedeutsam wurde. ${ }^{25}$ Schleiermacher nimmt die

22 Vgl. etwa Schleiermachers Deutung von Platons Theorie der Redekunst in seiner „Einleitung“ zum „Phaidros“, KGA IV/3, hg.v. Lutz Käppel und Johanna Loehr, Berlin/Boston 2016, S. 66-68.

23 Schleiermacher: Über die Religion. Reden an die Gebildeten unter ibren Verächtern, KGA I/2, S. 185-326, hier: 262. Vgl. Albert Meier, Alessandro Costazza, Gérard Laudin (Hg.): Kunstreligion (Bd. 1). Der Ursprung des Konzepts um 1800, Berlin 2011; dies.: Kunstreligion (Bd.2). Die Radikalisierung des Konzepts nach 1850, Berlin 2012; dies.: Kunstreligion (Bd.3). Diversifizierung des Konzepts um 2000, Berlin 2014. Ernst Müller: Ästhetische Religiosität und Kunstreligion in den Philosophien von der Aufklärung bis zum Ausgang des deutschen Idealismus, Berlin 2004.

24 Schleiermacher: Über die Religion, KGA I/2, S. 263. Vgl. Gunter Scholtz: „Schleiermacher und die Kunstreligion“, in: 200 Jahre „Reden über die Religion“. Akten des 1. Internationalen Kongresses der Schleiermacher-Gesellschaft. Halle 14.-17. März 1999, hg. v. Ulrich Barth und Claus-Dieter Osthövener, Berlin 2000, S. 515533, hier: 521.

25 So waren etwa August Wilhelm Schlegels Berliner Vorlesungen über die Kunstlehre (1801/02) für Schellings Vorlesungen über die Philosophie der Kunst in Jena (1802/03), 
Entwicklung der spekulativen Philosophien von Fichte, Schelling und Hegel um 1800 zur Kenntnis und sieht sich in einer gewissen Nähe $z u$ ibnen, wenngleich er den Absolutheitsansprüchen der spekulativen Systementwürfe nicht zustimmen konnte. Die Einordnung seiner „Reden" als einer Zuspitzung der Subjektivitätsphilosophie Jacobis in Hegels Abhandlung "Glauben und Wissen" von 1802 ist Schleiermacher jedenfalls nicht entgangen. ${ }^{26}$ Bereits in einem Brief an G. E. A. Mehmel, den Redakteur der Erlanger „Litteratur-Zeitung“, in der neben Fichte und Schelling auch Hegel (anonyme) Rezensionen publizierte, schrieb Schleiermacher am 21. April 1801, wohl als Antwort auf eine Einladung zur Mitarbeit: „[In] der speculativen Philosophie ist mir der Antheil, den die gegenwärtigen Häupter derselben in Deutschland an Ibrem Institut nehmen nicht entgangen; laßen indeß diese etwas merkwürdiges zurük, was Sie mir anvertrauen wollen, so werde ich es gern übernehmen. Eben so würde ich in dem Fache der praktischen und angewendeten Philosophie, mit Inbegrif der sogannten Aesthetik und der Theorie der Sprache gern Einiges arbeiten". ${ }^{27}$ Schleiermacher verfasste in der Folge fünf Rezensionen für die "Litteratur-Zeitung“" Mehmels, darunter eine von den "Charakteristiken und Kritiken" der Schlegel-Brüder und eine von Schillers Übersetzung des „Macbeth“ von Shakespeare. ${ }^{28}$

die er in Würzburg (1804/05) wiederholt hat, von Bedeutung. Vgl. Ernst Bebler: „Schellings Ästhetik in der Überlieferung von Henry Crabb Robinson“, in: Philosophisches Jahrbuch, Nr. 63, 1976, S. 133-176, hier: 137. Friedrich Wilhelm Joseph Schelling: Philosophie der Kunst und weitere Schriften (1796-1805), in: Historischkritische Ausgabe an der Bayerischen Akademie der Wissenschaften, Abt. II, Bd. 6,1, hg. von Christoph Binkelmann und Daniel Unger, Stuttgart 2018, S. 64. A. W. Schlegel: Vorlesungen über Ästhetik I (1798-1803), mit einem Kommentar und Nachwort herausgegeben von Ernst Behler (KAV 1), Paderborn, München u. a. 1989. Zum Verhältnis der Vorlesungen A. W. Schlegels zu seinen früheren Arbeiten im Zusammenhang mit F. Schlegel wie etwa dem „Athenaeum" vgl. Stefan Knödler: „August Wilhelm Schlegels Vorlesungen. Analoge und digitale Edition", in: Literaturkritik, Nr. 9, September 2014. URL: http://literaturkritik.de/id/1967 (abgerufen 23.06.2020).

26 Vgl. Brief 1574. An C. G. v. Brinckmann vom 19. 10. 1803, KGA V/7, hg.v. Andreas Arndt und Wolfgang Virmond, Berlin / New York 2005, S. 55. Georg Wilhelm Friedrich Hegel: „Glauben und Wissen“, in: Kritisches Journal der Philosophie 2, hg.v. G. W. F. Hegel und F. W. J. Schelling, Tübingen 1802, 1. Stück, S. 134137 (GW 4, S. 383-386).

27 Brief 1046, KGA V/5, hg.v. Andreas Arndt und Wolfgang Virmond, Berlin / New York 1999, S. 104. Zu Hegels Rezensionen in der Erlanger Literatur-Zeitung vgl. Walter Jaeschke: Hegel-Handbuch. Leben - Werk - Schule, Stuttgart 2016 (3. Auflage), S. 117-119.

28 Vgl. KGA V/6, hg.v. Andreas Arndt und Wolfgang Virmond, Berlin / New York 2005, „Historische Einführung“, S. XXXIX. 
Schleiermachers „Die Weihnachtsfeier. Ein Gespräch“ (1806) enthält ausführliche ästhetische Reflexionen, die überwiegend Sujets der frühromantischen Ästhetik betreffen wie etwa Johann Friedrich Reichardts Vertonung der "Weihnachtskantilene" von Matthias Claudius (1784), A. W. Schlegels Gedicht „Der Bund der Kirche mit den Künsten“ (1800) und Novalis' geistliches Lied „Wo bleibst du Trost der ganzen Welt" (1802). ${ }^{29}$ Nachdem Schelling auf Novalis' „Die Christenheit oder Europa“ mit seinem satirischen Gedicht „Epikureisch Glaubensbekenntnis Heinz Widerporstens" reagiert und darin auch Schleiermachers "Reden" karikiert hatte, rezensierte er die "Weihnachtsfeier" in der JALZ von 1807 durchaus freundlich, was Schleiermacher offenbar erfreut zur Kenntnis nabm, wie ein Brief an seinen Freund Carl Gustav von Brinckmann vom 1. März 1808 belegt. ${ }^{30}$ Für eine Rezension der Rede Schellings „Über das Verbältnis der bildenden Künste zu der Natur" (1807) für die „Heidelbergischen Jahrbücher der Literatur", um die ihn August Boeckh gebeten hatte, fand Schleiermacher, wohl wegen seines Umzugs von Halle nach Berlin aufgrund der Schließung der Universität Halle und der Kriegswirren, nicht die erforderliche Zeit. ${ }^{31}$ Diese Rede Schellings spielt in ibrer Beschreibung der Nähe von Kunst- und Naturproduktion für Schleiermachers Ästhetikvorlesungen jedoch eine wichtige Rolle, wovon etwa die Exzerpte und Aphorismen in seinen Notizen zur Ästhetik sowie die Anspielungen in den Marginalien für das Kolleg 1832/33 zeugen. $^{32}$

Nach seiner Berufung auf eine (zunächst) außerordentliche Professur für Theologie an der Universität Halle 1804, mit der auch eine Stelle als Universitätsprediger verbunden war, hatte Schleiermacher mit der Ausarbeitung seiner ethischen Vorlesungen begonnen. ${ }^{33}$ In seinem Brouillon zur philosophischen Ethik von 1805/06 entwickelte er das in den „Reden" zeitkritisch zugespitzte Verwandtschaftsverhältnis

29 Schleiermacher: Die Weihnachtsfeier. Ein Gespräch, KGA I/5, hg.v. Hermann Patsch, Berlin / New York 1995, S. 49-50, 59, 78-79. Vgl. Gunter Scholtz: Schleiermachers Musikphilosophie, Göttingen 1981, S. 26, 37, 138.

30 Jenaische Allgemeine Literatur-Zeitung 1807, Bd. 1, Nr. 58-59, Sp. 457-467, vom 9.-10. März. Brief 2650, KGA V/10, S. 68. In diesem Brief errät Schleiermacher Schelling als den Autor der anonymen Rezension.

31 Vgl. Briefe von A. Boeckh an F. Schleiermacher vom 7. Oktober 1808 und vom 5. April 1809: Brief 2859, KGA V/10, S. 286 und Brief 3193, KGA V/11, S. 225.

32 Vgl. Schleiermachers „Notizen zur Ästhetik I“ in diesem Band, S. 5-8, sowie seine „Marginalien zum Kolleg 1832/33“, S. 133.

33 Vgl. Nowak: Schleiermacher (Anm. 1), S. 147-150. 
von Religion und Kunst in systematischer Weise weiter. Dabei wird die Religion nicht mehr als "Anschauung des Universums" angesprochen, sondern im Rabmen der ethischen Funktionen des individuellen Symbolisierens als „Gefühl“ oder als die „eigentliche Sphäre des Gefübls im sittlichen Sein", während der Kunst die Aufgabe der Darstellung des Gefühls zukommt; daher könne gelten: „alle Menschen sind Künstler". ${ }^{34}$ Dabei bestimmt Schleiermacher das Gefühl und dessen Darstellung als einen unmittelbaren Zusammenhang, dem als einer Art Mitteilung durch mimische oder gestische Zeichen auch die Bedeutung einer indirekten Kommunikationsform zukommt. Der religiöse Aspekt der künstlerischen Darstellung liege hingegen darin, dass sie eine Reflexion über die Allgemeinheit impliziere, welche zugleich ibren vernünftigen Gehalt ausmache, so dass Schleiermacher im Rahmen der Ethik behaupten kann: die „wahre Ausübung der Kunst ist religiös". ${ }^{35}$ Daher ist die Kunst für Schleiermacher, obwohl sie als hervorbringende an die mechanischen Tätigkeiten angrenzt, eine selbstzweckmäßige und ungebundene Produktion des Individuums.

Als Schleiermacher 1807 in Berlin angekommen war, hielt er im Vorfeld der Universitätsgründung, in die er durch Wilhelm von Humboldt involviert worden war, erste (private) philosophische und theologische Vorlesungen, wurde nach der Eröffnung der Universität 1810 Professor und zugleich Dekan der theologischen Fakultät und übernabm das Amt eines Predigers an der Dreifaltigkeitskirche. ${ }^{36}$ Durch seine 1810 erfolgte Wahl in die Philosophische Klasse der Preußischen Akademie der Wissenschaften erhielt er die Möglichkeit, auch an der philosophischen Fakultät Vorlesungen zu halten, was Schleiermacher dann über 24 Jahre auch regelmäßig tat, zumeist ein Kolleg pro Semester. ${ }^{37}$ Dass seine Auffassung von der Ästhetik mit der Entwicklung

34 Schleiermacher: Brouillon zur Ethik 1805/06, hg.v. Hans-Joachim Birkner, auf Grundlage der Werke-Ausgabe v. Otto Braun, Hamburg 1981, S. 99-100. Vollständig lautet die Sentenz: „Trennt man nun beide Seiten, so besteht die Ethisierung der Darstellung darin, daß jede Darstellung ein reines Produkt des Gefübls sei: alle Künstler sollen Genien sein. Die Ethisierung des Gefübls aber, inwiefern es ein gemeinschaftliches werden soll, darin, daß jedes Gefühl in Darstellung übergehe: alle Menschen sind Künstler." (Ebd., S. 184).

35 Schleiermacher: Brouillon zur Ethik 1805/06 (Anm. 34), S. 100. Vgl. Anne Käfer: „Die wahre Ausübung der Kunst ist religiös. “ Schleiermachers Ästhetik im Kontext der zeitgenössischen Entwürfe Kants, Schillers und Friedrich Schlegels, Tübingen 2006.

36 Vgl. Nowak: Schleiermacher (Anm. 1), S. 215-221.

37 Vgl. Andreas Arndt und Wolfgang Virmond: Schleiermachers Briefwechsel (Verzeichnis) nebst einer Liste seiner Vorlesungen, Berlin 1992, S. 295-299. 
seiner philosophischen Ethik einhergeht, zeigen insbesondere die Berliner Ethikvorlesungen, in denen die Verwandtschaft von Kunst und Religion ein integraler Bestandteil bleibt, wenngleich ibr Verhältnis infolge der Entwicklung der Dialektik ab 1811 einen neuen Differenzierungsgrund erbält. In der Dialektik, die Schleiermacher offenbar schon seit seinen "Grundlinien einer Kritik der bisherigen Sittenlebre“ (1803) „im Kopf spukte“, entwickelte Schleiermacher die begrifflichen Grundlagen seiner philosophischen Systematik in kritischer Auseinandersetzung mit Fichtes Wissenschaftslehre, der seit der Eröffnung der Universität an der philosophischen Fakultät lehrte. ${ }^{38}$ In der Dialektik nähert Schleiermacher das bewusste Hervorbringen von allgemeingültigen Erkenntnissen der Philosophie und das individuelle Darstellen der Kunst einander an: „Das Philosophiren ist deshalb Kunst weil die Anwendung der Regeln nicht wieder unter Regeln zu bringen ist." 39 Schleiermachers Kunstauffassung äußert sich aber auch in den Vorlesungen über die christliche Sittenlehre, im Konzept des „darstellenden Handelns“, das er im Kolleg 1809/10 näher beschreibt: „Alle Kunst im höheren Sinne ist Darstellung und geht unmittelbar von einem Gefüble aus, welches nicht als Lust oder Unlust gesetzt wird. Alle Kunst im großen angesehen ist immer mit der Religion in Verbindung. Aller Cultus sucht sich zur Kunst auszubilden. [...] Auch alles darstellende Handeln des einzelnen wird künstlerisch, wenn auch nur mimisch. “40

In der Vorlesung über philosophische Ethik von 1812/13 bestimmt Schleiermacher die Kunst dann systematisch als ein Medium der Religion: „Wenn demnach das Bilden der Fantasie in und mit seinem Heraustreten Kunst ist, und der Vernunftgehalt in dem eigenthümlichen Erkennen Religion, so verhält sich Kunst zur Religion wie Sprache zum Wissen."41 Als Sprache der Religion enthält die Kunst aber nicht nur die Religion im engeren Sinn als Erkennen, das als

38 Vgl. Schleiermacher: Vorlesungen über die Dialektik, KGA II/10,1-2, hg.v. Andreas Arndt, Berlin / New York 2002, „Historische Einführung“, S. VIII-XVI.

39 Schleiermacher: Dialektik 1811, KGA II/10,1, S. 62.

40 Schleiermacher: Christliche Sitte 1809/10, \89 (Die christliche Sitte, Sämmtliche Werke, 1. Abteilung. Zur Theologie, 12. Band, hg.v. Ludwig Jonas, Berlin 1843, Beilage A, S. 29). Vgl. Jörg Dierken: „Darstellung - Ausdruck - Spiel. Zweckfreies Handeln und seine sittlichen Formen bei Schleiermacher", in: Christian Polke, Michael Firchow und Christoph Seibert (Hg.): Kultur als Spiel. Philosophisch-theologische Variationen, Leipzig 2019, S. 85-99.

41 Schleiermacher: Ethik 1812/13, hg.v. Hans-Joachim Birkner, Hamburg 1990, S. 74-75, \228. 
allgemeines Symbolisieren näher in das Gebiet der Dialektik falle, sondern auch „alles reale Gefühl“, das über die Persönlichkeit des Einzelnen hinaus eine Synthesis anzeige, die im physischen Bereich im Geist und im ethischen im Herz liege. ${ }^{42}$ Mit diesem weiten Begriff der Religion ist bereits der Gegenstand und mit dem Bilden der Fantasie ein Prozess skizziert, die für die Ästhetik als einer Theorie der Kunst nach Schleiermacher grundlegend sind. Ihre systematische Bedeutung als eine kritische Disziplin der Ethik wird im Rabmen der „vollkommenen ethischen Formen“ konkretisiert: „Es ist die Sache der kritischen Disciplin, welche wir jezt Aesthetik nennen, den Cyclus der Künste zu deduciren und das Wesen der verschiedenen Kunstformen darzustellen". ${ }^{43}$ Somit konzipiert Schleiermacher die Ästhetik als eine philosophische Disziplin, die mit dem Wesen der verschiedenen Kunstzweige auch dem systematischen Anspruch genügen muss, diese aus einem einheitlichen Begriff der Kunst zu entwickeln.

Neben der philosophischen Ethik enthält auch Schleiermachers Psychologie einige wichtige Bestandteile, die in seiner Ästhetik in Hinblick auf die Kunstproduktion von Bedeutung sind. ${ }^{44}$ Psychologie (1818) und Ästhetik (1819) sind nicht nur die letzten beiden philosophischen Disziplinen, zu denen Schleiermacher vollständige Vorlesungskonzepte ausgearbeitet hat, sondern sie sind auch inhaltlich miteinander verschränkt, etwa in Bezug auf das ästhetische Gefühl, die begeisterte Stimmung oder die den Produktionen der Kunst ähnelnden Erzeugungen des Traums. ${ }^{45}$

\section{Zum Kolleg 1819}

Erste briefliche Spuren eines Plans von Schleiermacher, ein Kolleg über Ästhetik durchzuführen, finden sich zum Jahreswechsel 1816/17. Schleiermacher schreibt an Joachim Christian Gaß: „, [A]ber leider fehlen mir noch ganze Disciplinen, an die ich nicht kommen kann, Einleitung ins Neue Testament, Psychologie, Aesthetik. Davon bin ich noch

42 Schleiermacher: Ethik 1812/13 (Anm. 41), S. 75, \ 229.

43 Schleiermacher: Ethik 1812/13 (Anm. 41), S. 126, \$ 232.

44 Schleiermacher: Vorlesungen über die Psychologie, KGA II/13, hg. v. Dorothea Meier, Berlin/Boston 2018.

45 Vgl. Thomas Lehnerer: Die Kunsttheorie Friedrich Schleiermachers, Stuttgart 1987, S. $114-152$. 
sehr weit entfernt. "46 Gut zwei Jahre später, zum Jahresende 1818, schreibt Schleiermacher seinem Jugendfreund Brinckmann bereits von einem konkreten Zeitraum: "Noch in den lezten Jahren habe ich eine Politik eine Dialektik eine Psychologie nach meiner eignen Weise vorgetragen, von denen ich hoffe wenn sie auf dem Papier ständen sollten sie sich Deines Beifalls erfreuen; und im nächsten Jahr denke ich an die Aesthetik zu gehn. "47 Kurze Zeit darauf ist der Plan gefasst, für das Sommersemester 1819 das erste Ästhetikkolleg anzukündigen. Davon berichtet Schleiermacher seinem Kollegen Immanuel Bekker am 9. Januar $1819 \mathrm{im}$ Zusammenhang mit der Ankunft Hegels in Berlin: „Bei uns ist nun Hegel angekommen, und man muß sehn, wie er sich auf die Länge hält; Klagen über Unverständlichkeit werden freilich schon gehört, aber vielleicht giebt sich das. Mir ist es lieb, daß ich nun meine philosophischen Segel wenigstens einziehen kann, so bald ich will. Vor der Hand will ich nun noch im Sommer ein neues Kollegium lesen, nämlich Aesthetik; daneben soll meine Dogmatik fertig werden, und weiter will ich nichts thun." ${ }^{48}$ Entlastung erhoffte sich Schleiermacher von der Berufung Hegels wohl nicht nur, um seine eigenen wissenschaftlichen Projekte intensiver bearbeiten zu können, sondern wohl auch deshalb, weil der philosophische Lehrbetrieb der Berliner Universität seit dem Tod Fichtes 1814 nicht hinreichend aufgestellt war: Neben Karl Wilhelm Ferdinand Solger, der als Spezialist der antiken und romantischen Ästhetik auch Kollegien über Logik, Dialektik, Politik- und Rechtsphilosophie hielt, lehrte kein ausgewiesener Philosophieprofessor am philosophischen Institut. Dafür sprangen gelegentlich Professoren benachbarter Disziplinen ein, wie eben Schleiermacher oder auch Ernst Heinrich Toelken und August Boeckh, wobei die letzteren beiden überwiegend die antike Kunst behandelten; Privatdozenten unterstützten zusätzlich den

46 Brief von F. Schleiermacher an Joachim Christian Gaß, vom 29. Dezember 1816 bis 2. Januar 1817, in: Friedrich Schleiermachers Briefwechsel mit J. Chr. Gaß, mit einer biographischen Vorrede hg.v. Wilhelm Gaß, Berlin 1852, S. 128.

47 Brief von F. Schleiermacher an C. G. v. Brinckmann vom 31. Dezember 1818, in: Aus Schleiermachers Leben. In Briefen, Bd.4, hg.v. Wilhelm Dilthey, Berlin 1863, S. 241.

48 Brief von F. Schleiermacher an A. I. Bekker, vom 9. Januar 1819 bis zum 16. Januar 1819, in: Friedrich Schleiermacher: Briefwechsel mit August Boeckh und Immanuel Bekker. 1806-1820, für die Litteraturarchiv-Gesellschaft in Berlin [hg.v. Heinrich Meisner], Berlin 1916, S. 102. 
Lehrbetrieb. ${ }^{49}$ Nach dem plötzlichen Tod Solgers im Herbst 1819, hielten Hegel und Schleiermacher ibre Vorlesungen über die Philosophie der Kunst bzw. Ästhetik regelmäßig, aber nie im selben Semester. ${ }^{50}$

Die ersehnte Fertigstellung seiner Dogmatik erforderte von Schleiermacher aber trotz dieser institutionellen Bedingungen ein bohes Maß an intensiver Arbeit, was die Vorbereitung seines Ästhetikkollegs wohl erschwerte. In einem Brief an seinen Schüler August Twesten vom 14. März 1819 schreibt Schleiermacher: „[U]nd dann wünsche ich gar sehr im Sommer und Herbst meine Dogmatik fertig zu machen. Nun freilich ist es schlimm, daß ich für den Sommer ein neues Collegium angekündigt habe, das ich schon lange im Schilde führe, aber wozu noch nichts vorbereitet ist, nämlich Aesthetik. "51

Gut einen Monat später, am 19. April 1819, beginnt Schleiermacher seine erste Ästhetikvorlesung in fünf wöchentlichen Stunden und hält sie bis zum 7. August; 108 Hörer schrieben sich für das Kolleg ein. ${ }^{52}$ Im Lektionskatalog der Berliner Universität für das Sommersemester 1819 findet sich die entsprechende Ankündigung unter der Rubrik „Philosophische Wissenschaften“: „Aesthetik, Herr Prof. Schleiermacher, fünfmal wöchentlich von 6-7 Uhr Morgens. "53 $\mathrm{Ne}$ ben der Ästhetik gab Schleiermacher in diesem Semester zwei theologische Kollegien: eines über die Hermeneutik bezüglich des Neuen Testaments und eines über die Briefe an die Hebräer. ${ }^{54}$

Laut den brieflichen Zeugnissen hatte Schleiermacher nur eine sehr begrenzte Vorbereitungszeit für die Ausarbeitung seiner Ästhetik gehabt, auch kosteten die beiden anderen Kollegien sowie weitere Verpflichtungen etwa gegenüber der Gesangbuchskommission nicht nur relativ viel Arbeitszeit, sondern erforderten auch organisatorisches

$49 \mathrm{Vgl}$. Wolfgang Virmond (Hg.): Die Vorlesungen der Berliner Universität 18101834, nach dem deutschen und lateinischen Lektionskatalog sowie den Ministerialakten, Berlin 2011.

50 Hegel gab nach 1817 und 1818 in Heidelberg, 1820/21, 1823, 1826 und 1828/29 in Berlin Vorlesungen über die Philosophie der Kunst. Vgl. Jaeschke: Hegel Handbuch (Anm. 27), S. 413.

51 Brief von F. Schleiermacher an August D. C. Twesten vom 14. März 1819, in: D. August Twesten nach Tagebüchern und Briefen, hg. v. C. F. Georg Heinrici, Berlin 1889, S. 342.

52 Vgl. Virmond (Hg.): Die Vorlesungen der Berliner Universität (Anm. 49), S. 191.

53 Ebd.: „Aestheticen docebit quinquies p. hebd. hor. VI-VII. matutina."

54 Vgl. Nowak: Schleiermacher (Anm. 1), S. 300. Vgl. Virmond (Hg.): Die Vorlesungen der Berliner Universität (Anm. 49), S. 185. 
Geschick. So liegen nur etwa fünf Wochen zwischen Schleiermachers brieflicher Aussage an Twesten vom 14. März, „noch nichts vorbereitet" zu haben, und dem Beginn des Kollegs am 19. April 1819. Dass es Schleiermacher dennoch gelang, eine eigenständige und umfassende Konzeption der Ästhetik auszuarbeiten, verdankt sich dem Umstand, dass er bereits über einen breiten Fundus an ästhetischen Kenntnissen verfügte und einen systematischen Ansatz zur Ästhetik im Rahmen seiner Ethik ausgearbeitet hatte, deren Veröffentlichung er weiterhin plante. Dies belegt auch seine Aussage in einem Brief an Bekker fünf Tage nach Beginn des Kollegs; Schleiermacher schreibt am 24. April: „Nach meiner Ethik fragen Sie? nicht nur sie schläft sehr sanft sondern auch die angefangene Dogmatik rubt, und ich zweifle ob die Aesthetik die ich nun lese und die Hermeneutik über die ich leider mein Heft verloren habe, und der Brief an die Hebräer den ich auch einmal wieder durcharbeiten muß mich dazu kommen lassen werden, sie wie ich gehofft hatte diesen Sommer zu vollenden. Die Aesthetik knüpft indeß an die Ethik an, und so kommt sie mir wenigstens nicht aus dem Sinne. "55 Wohl aufgrund der geringen Vorbereitungszeit scheint der Arbeitsaufwand auch während der Durchführung des Kollegs nicht wesentlich abgenommen zu haben. Schleiermacher teilt $G a \beta$ am 28. April in einem Brief mit: "Die Aesthetik kostet Zeit“, und am 2. Juni ebenfalls an Gaß: „Meine Kollegia kosten mich diesmal unverhältnißmäßig viel Zeit, da ich für die Aesthetik nichts vorgearbeitet habe"; im Postskriptum heißt es dann: „Meine Aesthetik gefällt mir bis jezt nicht übel aber ich weiß noch nicht wie ich fertig werden soll. " 56

Neben den wissenschaftlichen Anforderungen musste Schleiermacher auch mit politischen Verhältnissen umgehen, inbesondere der restaurative Kurs der preußischen Regierung nach den Befreiungskriegen, dem Wiener Kongress und den Karlsbader Beschlüssen betraf zum Teil direkt seine öffentliche Tätigkeit als Prediger und Universitätsdozent: Er wurde offiziell verdächtigt, demagogisch umtriebig zu sein. ${ }^{57}$ Infolge der Affäre um den Berliner Theologieprofessor de Wette verschärfte sich die Situation, nachdem die Ministerial-Kom-

\footnotetext{
55 Brief von F. Schleiermacher an A. I. Bekker vom 24. April 1819, in: Schleiermacher: Briefwechsel mit August Boeckh und Immanuel Bekker (Anm. 48), S. 108-110.

56 Brief von F. Schleiermacher an Joachim Christian Gaß vom 28. April und vom 2. Juni 1819, in: Schleiermachers Briefwechsel mit J. Chr. Gaß (Anm. 46), S. 173174.

57 Vgl. Nowak: Schleiermacher (Anm. 1), S. 379-381.
} 
mission, die den Fall de Wette aufarbeitete, einen Brief des Studenten Bernhard Lindenberg auswertete, in dem dieser von einem Umtrunk auf dem Berliner Pichelsberg vom 2. Mai 1819 berichtet, an dem neben einigen Studenten und Burschenschaftlern auch die Professoren Schleiermacher und Hegel sowie der noch lehrende de Wette teilgenommen hätten. Laut diesem Brief sagte Lindenberg zu später Stunde noch zu Schleiermacher: „Ach Schleiermacher, wie wirst Du in Deiner Ästhetik morgen um $6 \mathrm{Ubr}$ Dich finden. "58 Eine baldige Rücknahme der offiziellen Verdächtigungen gegenüber Schleiermacher konnte unter diesen Umständen vorerst nicht erfolgen. Schleiermachers erste Ästhetikvorlesung entstand somit in einem politischen Klima, in dem die in ihr hervorgehobene freie Produktivität von Kunst und Wissenschaft in ihrer Entfaltung durchaus bedroht war.

Überliefert ist das Ästhetikkolleg 1819 durch Schleiermachers bis zur 64. Stunde fortgeführtes und dann abgebrochenes Vorlesungsmanuskript, auf dessen Titelblatt er notierte: „angef[angen] 1819 d[en] 19. April". Dieses Kollegheft verwendete Schleiermacher auch für die beiden nachfolgenden Kollegien 1825 und 1832/33, was die teilweise umfangreichen (im Fall des Kollegs 1832/33 mit neuer Stundenzählung versehenen) Randbemerkungen belegen. Schleiermachers ebenfalls erhaltene „Notizen zur Ästhetik“, zwei Hefte kleineren Umfangs, legen nahe, dass er das Kolleg nicht unvorbereitet hielt, weil sich darin auch einige der Durchführung offenbar vorausgehende Exzerpte und Kommentare zu Quellen der zeitgenössischen Ästhetik (etwa Schelling, Ast, Goethe) befinden. Auch über den allgemeinen Begriff der Kunst und die Spezifik der einzelnen Kunstzweige machte sich Schleiermacher in diesen Notizen Gedanken. Aufzeichnungen zur "Musik“, die nicht näher datiert werden können und vermutlich nicht eigens für das Kolleg angefertigt wurden, zeugen von Schleiermachers musiktheoretischen Kenntnissen.

Vorlesungsnachschriften zum Kolleg 1819 sind im Original nicht überliefert. Carl Lommatzsch berichtet in seiner Edition von 1842 von einer Vorlesungsnachschrift des "Professors Wigand". ${ }^{59}$ Diese Nachschrift des bis 1819 Theologie studierenden Eugen Anton Wigand, der ab 1821 Professor am Berliner Friedrich-Wilhelm-Gymna-

58 Vgl. Nowak: Schleiermacher (Anm. 1), S. 382.

59 Schleiermacher: Vorlesungen über die Aesthetik. Aus Schleiermachers handschriftlichem Nachlasse und aus nachgeschriebenen Heften, hg.v. Carl Lommatzsch, in: Friedrich Schleiermachers sämmtliche Werke, 3. Abt., 7. Bd., Berlin 1842, S. X. 
sium wurde, ist nicht erhalten. Auch Lommatzsch berichtet nichts über den Verbleib dieser Nachschrift, von der er nur zwei kurze Ausschnitte über die Poesie wiedergibt. Weitere erschlossene Hörer des Kollegs sind Ludwig Jonas, Gustav Parthey und Friedrich Blubme. Allein von Blubme ist eine Nachschrift als Sekundärüberlieferung in der Edition von Rudolf Odebrecht erhalten; aufgrund der Editionsund Kompilationstechnik Odebrechts bricht diese Nachschrift jedoch mit Schleiermachers Kollegheft in der 64. Stunde ab. ${ }^{60}$

Weil ein Tageskalender Schleiermachers für das Jabr 1819 nicht überliefert ist, können die Daten der einzelnen Stunden nur nach Abgleich mit den sporadischen Mitteilungen Odebrechts aus der Nachschrift Bluhme ermittelt werden, wo etwaige Stundenausfälle oder -verschiebungen nicht angegeben sind:

16.5.: 19. Stunde; 27.5.: 26. Stunde; 8.6.: 32. Stunde; 21.6.: 39. Stunde; 29.6.: 45. Stunde; 7.7.: 51. Stunde; 13.7.: 54. Stunde. ${ }^{61}$ Werden von dieser 54. Stunde die Termine bis zum angeblichen Ende am 7. August zusammengezäblt, hätte das Kolleg über ca. 73 Stunden verlaufen müssen.

Sein Kollegheft beginnt Schleiermacher mit einer knappen historischen Einleitung über den Gegenstand und den Begriff der Ästhetik in Hinblick auf die Kunst als einer Produktion, die der Naturproduktion ähnlich sei, aber durch menschliche Tätigkeit bewusst entstehe. Nach der Einleitung ist die Ästhetik in zwei Hauptteile untergliedert: ein allgemeiner spekulativer Teil, in dem das Wesen der Kunst erörtert wird, und ein besonderer Teil, der die einzelnen Künste beinhaltet.

Im allgemeinen Teil wird die Ästhetik aus den Grundsätzen der Ethik abgeleitet („Ethische Lemmata“), die als allgemeine Wissenschaft der Vernunfttätigkeit auch die Grundlage der künstlerischen Produktivität darstelle. Gemäß dieser Ableitung ist die Kunstausübung eine der erkennenden Funktion ähnliche individuelle Tätigkeit, die ibren Grund im Gefühl hat. Ausgehend von der unmittelbaren Darstellung des Gefühls in der Gefüblsäußerung im Rabmen der Ethik konstatiert Schleiermacher, dass ein Akt der „Besinnung“ zwischen die Gefühlserregung und ibre Darstellung treten müsse, damit ein genuines Kunstwerk entstehe. Schön ist diese Darstellung dann,

60 Friedrich Schleiermachers Ästhetik, im Auftrage der Preußischen Akademie der Wissenschaften und der Literatur-Archiv-Gesellschaft zu Berlin nach den bisher unveröffentlichten Urschriften, hg. v. Rudolf Odebrecht, Berlin 1931.

61 Vgl. Schleiermacher: Ästhetik, hg.v. Odebrecht (Anm. 60), S. 80, 101, 122, 145, 165, 182, 191. 
wenn in den internen Relationen ibrer Gestalt eine Verbindung von elementarischer und organischer Vollkommenheit vorliegt, die dem Ideal als einer möglichst mangellosen Erscheinung mit strenger $\mathrm{Ge}$ messenheit entspricht.

Mit der Erörterung der drei wesentlichen Momente der Kunsttätigkeit greift Schleiermacher auch auf seine Kenntnisse der Psychologie zurück: 1. die Begeisterung oder Erregung des Gefühls, 2. den Akt der Besinnung, der die innere Urbildung (durch die Fantasie) hervorbringe, und 3. die äußerliche Darstellung des Kunstwerks. Weil das Gefühl nach Schleiermacher nur vermittelt durch die Besinnung in die Kunstproduktion einfließt und dadurch sein momentaner Charakter aufgehoben wird, musste er einen neuen Begriff für diesen vermittelten Grund suchen, den er in der „Stimmung“ findet, die er als einen „Durchschnitt festgehaltener Affectionsmomente" bezeichnet. ${ }^{62}$ Kunst spekulativ als ein "organisch werden der Stimmung" und "freie menschliche Production" zu fassen, die einem allgemeinen "Kunsttrieb“ entspringe, legt es nahe, Schleiermachers Ästhetik als eine Produktionsästhetik zu charakterisieren, die sich von wirkungsästhetischen Ansätzen der Empfindsamkeit ebenso absetzt wie von formalästhetischen Erklärungen der Kunst im Kantischen Sinne.

Die Fundierung der Kunstproduktion in der Stimmung ermöglicht es Schleiermacher schließlich auch, die einzelnen Künste einheitlich zu bestimmen: „Begeisterung aber ist nichts anderes als das Erregtwerden der freien Production durch die Stimmung. Also ist sie auch an sich dieselbe in allen Künsten, das jedesmal erneuerte Werden der bestimmten Kunst selbst aus dem allgemeinen Kunsttriebe."63 Das Verhältnis der einzelnen Künste zueinander entwickelt Schleiermacher dann aufgrund der Richtung, die der allgemeine Kunsttrieb auf die individuelle Begeisterung und die Organe ausübt, durch die Kunstwerke sinnlich wahrnehmbar dargestellt und aufgefasst werden. Demnach sei die spezifische Begeisterung für körperliche Bewegungen und musikalische Töne der Anfang der subjektiven Kunstzweige Mimik und Musik, die Begeisterung für regelmäßige bzw. organische

62 Schleiermacher: Kollegheft Ästhetik 1819, in diesem Band S. 54. Zur Genese von Schleiermachers Begriff der Stimmung vgl. Peter Grove: „Der Grundton aller unserer Gefüble. Schleiermachers Begriff der Stimmung", in: Der Mensch und seine Seele. Bildung - Frömmigkeit - Ästhetik, Akten des Internationalen Kongresses der Schleiermacher-Gesellschaft in Münster, September 2015, hg. v. Arnulf von Scheliha und Jörg Dierken, Berlin 2017, S. 533-552.

63 Schleiermacher: Kollegheft Ästhetik 1819, in diesem Band S. 68-69. 
Gestaltungen im Medium der anorganischen Materie hingegen der Anfang der objektiven Kunstzweige Architektur, Skulptur etc. Diese erkenntnistheoretisch und psychologisch fundierte Ableitung der einzelnen Künste bringt Schleiermacher dann zu der Einteilung der drei Abteilungen: 1. „,begleitende Künste“ (Mimik, Musik) und 2. „bildende Künste" (Architektur, Skulptur). Da das Manuskript von 1819 mit der 64. Stunde inmitten der Behandlung der "Skulptur" abbricht, kann auf den weiteren Verlauf nur aus den nachfolgenden Kollegien geschlossen werden. Demnach müssten die bildenden Künste abschließen mit der „Malerei“ und auf diese als 3. Abteilung die „Poesie" folgen, welche die subjektiven und objektiven Aspekte der beiden anderen Abteilungen integriert.

Eine Binnenunterteilung, die alle Kunstzweige durchläuft, findet Schleiermacher zudem im Unterschied zwischen religiösem und geselligem Stil sowie im historischen Gegensatz zwischen Antike und Moderne.

\section{Zum Kolleg 1825}

Schleiermachers zweites Ästhetikkolleg wird im Lektionskatalog der Berliner Universität für das Sommersemester 1825 angekündigt: „Aesthetik trägt Hr. Prof. Schleiermacher wöchentlich fünfmal von 6-7 Ubr Morgens vor"; das Kolleg verlief vom 11. April bis zum 9. September 1825, eingeschrieben waren 81 Hörer. ${ }^{64}$ Neben der Ästhetik hielt Schleiermacher in diesem Semester nur eine theologische Vorlesung über seine inzwischen veröffentlichte Dogmatik (die erste Auflage der „Glaubenslehre“ erschien 1821/22), die er allerdings täglich über zwei Stunden, von 7 bis 9 Uhr morgens, direkt im Anschluss an die Ästhetik veranstaltete. ${ }^{65}$ In dem bekannten Briefwechsel Schleiermachers aus dem Jahr 1825 ist über das Ästhetikkolleg daher wohl weniger die Rede als von dem Plan einer Revision der Dogmatik. Offenbar waren die Kritiken an der "Glaubenslehre" eindringlicher ausgefallen als von Schleiermacher erwartet, auch war er selbst mit einigen zu "weitschweifigen“ Passagen nicht ganz zufrieden, wie er

64 „Privatim aestheticen seu theoriam artium universalem tradet quinquies hor. VIVII. matut." Virmond (Hg.): Die Vorlesungen der Berliner Universität (Anm. 49), S. 383.

65 Vgl. Virmond (Hg.): Die Vorlesungen der Berliner Universität (Anm. 49), S. 375. 
in einem Brief an Twesten vom 8. September 1825 schreibt. ${ }^{66}$ Die Fertigstellung seiner Ethik trieb Schleiermacher zu dieser Zeit aber offenbar genauso um, wie derselbe Brief an Twesten belegt: „Dann wartet Reimer schon auf die Revision der Dogmatik, an die ich aber doch erst im Sommer kommen werde, und dann scheint mir doch die schon halb fertige Ethik ein größeres Recht zu haben, wiewohl auch sie noch warten muß". ${ }^{67}$

Diese arbeitsintensiven wissenschaftlichen Projekte haben wohl dazu beigetragen, dass Schleiermacher seine Ästhetik in diesem Semester ohne größere Veränderungen gegenüber dem sechs Jahre früher gehaltenen Kolleg vorgetragen hat, möglicherweise aber sah er auch keinen Grund für Veränderungen, weil er mit der Konzeption nicht unzufrieden war. Der restaurative Kurs der preußischen Regierung hatte sich inzwischen jedenfalls soweit gemäßigt, dass Schleiermacher keine Beobachtungen oder Repressionen wegen demagogischer Umtriebe mehr befürchten musste. Er nutzte die ihm verbleibende Zeit auch für die Ausbildung seiner Kunstkenntnisse, setzte seine Singstunden im Chor der Berliner Singakademie gelegentlich fort oder besuchte Opernaufführungen, wie etwa Webers „Freischütz" (25. Juli 1821), Glucks „Iphigenie in Aulis“ (11. Februar 1822 und 27. Januar 1823) und Grauns „Der Tod Jesu“ (28. März 1823 und 16. April 1824). ${ }^{68}$

Aus Schleiermachers Hand sind für das Kolleg 1825 nur einige Randnotizen in seinem ursprünglichen Kollegheft erhalten, auf dessen Titelblatt er am Rand das Anfangsdatum notiert hat: „angef[angen] 1825 d[en] 11. April“. Außerdem sind noch zwei kleinere Texte aus dem weiteren Kontext von Schleiermachers Beschäftigung mit der Ästhetik in dieser Zeit erhalten: ein Notizzetttel zur zweiten Auflage von Friedrich Bouterweks "Ästhetik", auf dem er einige ästhetische Kategorien zusammenfasst, sowie ein Notizzettel, auf dem Schleiermacher einen Ausschnitt der musikalischen Struktur des Trauerliedes "Wie sie so sanft rubn" von Friedrich Beneken beschreibt. ${ }^{69}$

66 Brief von F. Schleiermacher an August D.C. Twesten vom 8. September 1825, in: D. August Twesten nach Tagebüchern und Briefen (Anm. 51), S. 382.

67 Ebd.

68 Vgl. Wolfgang Virmond: „Schleiermacher und die Musik nach Auskunft seiner Tagebücher" (unveröffentlichtes Manuskript). Carl Dablhaus (Hg.): Studien zur Musikgeschichte Berlins im frühen 19. Jahrhundert, Regensburg 1980.

$69 \mathrm{Vgl}$. den „editorischen Bericht" zum Anhang "Notiz zur Ästhetik von Bouterwek" und „Notiz zu einem Trauerlied“. 
In Schleiermachers Tageskalender 1825 sind folgende Stundeneinträge zum Kolleg 1825 notiert:

11.4.: „1. Stunde Aesthetik“; 15.4.: „5te Stunde Aesthetik“; 18.4.: „6. Stunde Aesthetik“; 22.4.: „Aesthetik 10“; 25.4.: „Aesthetik 11 “; 26.4.: „Aesthetik 12 “; 28.4.: „Aesthetik 13“; 29.4.: „Aesthetik 14“; 2.5.: 2.5.: „Aesthetik 15 “; 6.5.: „Aesthetik 19“; 9.5.: „Aesthetik 20“; 13.5.: „Aesthetik 23“; 16.5.: „Aesthetik 24“; 20.5.: „Aesthetik 28“; 26.5.: „Aesthetik 29“; 27.5.: „Aesthetik 30“; 30.5.: „Aesthetik 31“; 3.6.: „Aesthetik 35“; 6.6.: „Aesthetik 36“; 10.6.: „Aesthetik 40“; 13.6.: „Aesthetik 41“; 17.6.: „Aesthetik 44“; 20.6.: „Aesthetik 45“; 23.6.: „Aesthetik 48“; 14.7.: „Aesthetik 49“; 15.7.: „Aesthetik 50“; 18.7.: „Aesthetik 51 “; 22.7.: „Aesthetik 55“; 25.7.: „Aesthetik 56“; 29.7.: „Aesthetik 59“; 1.8.: „Aesthetik 60“; 2.8. „Architectur beendigt“; 3.8.: „Kollegia [...] ausgesezt“; 5.8.: „Aesthetik 63 “; 8.8.: „Aesthetik 64“; 12.8.: „Aesthetik 68 Mablerei angefangen“; 15.8.: „Aesthetik 69“; 19.8.: „Aesthetik 73 “; 22.8.: „Aesthetik 74 bildende Künste beendigt“; 23.8.: „Aesthetik 75 Redende Künste angefangen“; 26.8.: „Aesthetik 78“; 29.8.: „Aesthetik 79“; 2.9.: „Aesthetik 83 alte Poesie geschlossen; neue eingeleitet“; 5.9.: „Aesthetik 84“; 9.9.: „Aesthetik 88 und geschlossen“. Während der dreiwöchigen Vorlesungspause zwischen dem 23.6. und dem 14.7. unternahm Schleiermacher eine Rügenreise, die auch in seinem Tageskalender 1825 dokumentiert ist. ${ }^{70}$

Insgesamt sind vier Vorlesungsnachschriften vom Kolleg 1825 bekannt, von denen drei (teils fragmentarisch) erhalten sind: jeweils eine von Ernst Moritz Heinrich Bindemann, von Friedrich Adolf Trendelenburg und von einem anonymen Nachschreiber. Die Nachschrift des "Predigers Braune zu Wittstock" - Heinrich Wilhelm Julius Braune, der 1844 zum Superintendenten in Mittenwalde bei Zossen ernannt wurde, die Lommatzsch neben der von „Bindemann" bei der Erstedition von 1842 noch vorlag und aus der er einige Passagen zur Poesie im Anhang wiedergibt, konnte jedoch nicht aufgefunden werden und muss als verschollen gelten. ${ }^{71}$

Der von den erhaltenen Nachschriften dokumentierte inhaltliche Aufbau des Kollegs erlaubt den Schluss, dass es Schleiermacher ohne größere Veränderungen gegenüber dem von 1819 vorgetragen hat. Die wenigen Marginalien im Kollegheft 1819, die sicher in das Jahr 1825 datiert werden können, stützen diese Annahme. Auch Lommatzsch war der Auffassung, dass dem Kolleg von 1825 der Entwurf von 1819 zugrunde lag und zwischen beiden keine großen Differenzen bestehen. ${ }^{72}$ Odebrecht behauptet dasselbe, allerdings aufgrund der inzwischen als falsch erwiesenen Annabme, bei der anonymen Nach-

\footnotetext{
70 Vgl. Schleiermacher: Tageskalender 1825, erarbeitet von Elisabeth Blumrich, in: schleiermacher digital / Schleiermachers Tageskalender 1808-1834 (Anm. 3). URL: https://schleiermacher-digital.deltageskalender/index.xql (abgerufen 23.06.2020).

71 Vgl. Schleiermacher: Ästhetik, hg.v. Lommatzsch (Anm. 59), S. X, 691-710.

72 Vgl. Schleiermacher: Ästhetik, hg.v. Lommatzsch (Anm. 59), S. V.
} 
schrift handele es sich um ein Autograph Schleiermachers. ${ }^{73}$ Somit kann der inhaltliche Aufbau des Kollegs 1825, wie er in den Vorlesungsnachschriften dokumentiert ist, auch dazu beitragen, denjenigen Teil des Kollegs 1819 zu rekonstruieren, den Schleiermachers Kollegheft und Odebrechts Auszüge aus der Nachschrift Blubme nicht enthalten, weil beide bei der Behandlung der Skulptur abbrechen. Schleiermacher hatte folglich auch 1819 nach der Skulptur die Malerei und abschließend die Poesie behandelt.

Friedrich Trendelenburg, der heute als ein Mitbegründer des Neukantianismus gilt und 1824/25 u.a. bei August Boeckh und Henrich Steffens an der Berliner Universität gehört hatte, schreibt in einem Brief an seinen Vater über den Besuch von Schleiermachers Ästhetikkolleg 1825: „Es ist fesselnd, wie Schleiermacher in der Aufbaunng einer philosophischen Wissenschaft sucht und findet und uns selbst mitsuchen und mitfinden lässt. Der Weg ist schwer, weil Geist dazu gehört und strenge Consequenz. In den philosophischen Vorträgen pflegt man sonst das Gefundene mit seinen Beweisen, oft wie vom Dreifuss herunter, zu geben; aber die Frage: wie kam man zu diesem Ziel? bleibt unbeantwortet. Schleiermacher lehrt selbst den Weg gehen und in dieser Hinsicht, weniger in Rücksicht der Ergebnisse, die spärlicher zum Vorschein kommen, eben weil sie gefunden werden sollen, hörte ich nie etwas Aehnliches. Ich wüsste nicht, wo ich mehr lernen könnte für die Gedankenentwickelung in mir und in anderen. "74

Diese Aussage Trendelenburgs verdeutlicht die auch von anderen Hörern (auch seiner Predigten) gerühmten rhetorischen Qualitäten Schleiermachers, der seine Vorlesungen offenbar aufgrund nur weniger Notizen oftmals frei hielt und dabei Gedanken ausfübrte, Beispiele anbrachte und Exkurse entfaltete, die in seinen eigenen Manuskripten nicht vorkommen; darin liegt zugleich auch ein Teil der Bedeutung, die die Vorlesungsnachschriften für das nähere Verständnis von Schleiermachers wissenschaftlicher Tätigkeit tragen. ${ }^{75}$

73 Vgl. Schleiermacher: Ästhetik, hg.v. Odebrecht (Anm. 60), S. XXIX.

74 Zit. in: Ernst Bratuscheck: Adolf Trendelenburg, Berlin 1873, S. 45. Vgl. Klaus Christian Köhnke: Entstehung und Aufstieg des Neukantianismus, Frankfurt am Main 1996, S. 446.

$75 \mathrm{Vgl}$. Holden Kelm: „Schleiermachers Vorlesungseditionen im historischen Vergleich", in: Jörn Bohr (Hg.): Kolleghefte, Kollegnachschriften und Protokolle. Probleme und Aufgaben der philosophischen Edition. Beihefte zu „edito“, Bd. 44, Berlin/Boston 2019, S. 37-53. 


\section{Zum Kolleg 1832/33}

Sein letztes Ästhetikkolleg hielt Schleiermacher im Wintersemester 1832/33. Unter der Rubrik „Kunstgeschichte und Kunstlehre“ wird im Lektionskatalog der Berliner Universität angekündigt: „Ästhetik, Hr. Dr. Schleiermacher, Mitgl. d. Königl. Akad. d. Wiss. wöchentl. fünfmal Morgens von 7-8 Uhr"; das Kolleg verlief vom 23. Oktober 1832 bis zum 29. März 1833, 71 Hörer waren eingeschrieben. ${ }^{76} \mathrm{Ne}$ ben dieser hielt Schleiermacher in diesem Semester zwei theologische Vorlesungen, eine über die Hermeneutik und deren Anwendung auf das Neue Testament und eine über das Matthäus-Evangelium. ${ }^{77}$

In den sieben Jahren zwischen seinen beiden letzten Ästhetikkollegien hat sich Schleiermacher weiterhin mit Kunst und Kunsttheorie beschäftigt. Er erlebte etwa am 11. März 1829 zusammen mit anderen Gästen wie Zelter und Hegel die Wiederaufführung von Bachs Matthäus-Passion in der Berliner Singakademie in der Bearbeitung von Felix Mendelssohn Bartholdy, verfolgte die Entstehung des klassizistischen (Alten) Museums auf der Berliner Museumsinsel, das nach einem Entwurf von Friedrich Schinkel erbaut und 1830 eröffnet wurde, und besuchte 1832 offenbar die 27. Kunstausstellung der Königlichen Akademie der Künste in Berlin. An der Akademie der Wissenschaften trug er 1831 und 1832 „Über den Umfang des Begriffs der Kunst in Bezug auf die Theorie derselben" vor, ein dritter Vortrag zum selben Thema war geplant, konnte aber aufgrund der schnell fortschreitenden Krankheit Schleiermachers zu Beginn des Jahres 1834 nicht mehr realisiert werden. ${ }^{78}$

Aus Schleiermachers Hand sind für das Kolleg 1832/33 umfangreiche Marginalien zu seinem ursprünglichen Kollegheft erhalten, die sich von dem Entwurf für die Kollegien 1819 und 1825 unterscheiden und eine eigene Stundenzählung aufweisen; sie brechen in der Behandlung der Architektur etwa mit der 68. Stunde ab. ${ }^{79}$

76 Vgl. Virmond (Hg.): Die Vorlesungen der Berliner Universität (Anm. 49), S. 712: „Privatim aestheticen docebit quinquies p. hebd.h. VII-VIII. matutina." Erst ab dem Sommersemester 1822 gibt es „Kunstgeschichte“ als eigene Rubrik im Lektionskatalog (vgl. ebd. S. 712 und S. 285).

77 Vgl. Virmond (Hg.): Die Vorlesungen der Berliner Universität (Anm. 49), S. 695.

78 Schleiermacher: „Über den Umfang des Begriffs der Kunst in Bezug auf die Theorie derselben. " 1.-3. Abhandlung, KGA I/11, hg.v. Martin Rössler, Berlin / New York 2002, S. 725-742, 769-786, 787-794.

79 Es finden sich noch zwei Marginalien zum Themenkreis der Skulptur, die möglicherweise zur 89. und 90. Stunde gehören. Vgl. dazu den „Editorischen Bericht“ zu Schleiermachers „Marginalien 1832/33“. 
In Schleiermachers Tageskalender 1832 sind folgende Vorlesungsstunden notiert:

23.10.: „Alle drei Collegia angefangen“; 26.10.: „4te Stunde“; 29.10.: „5te Stunde“; 31.10.: „7te Stunde“; 1.11.: „8te Stunde“; 2.11.: „9. Stunde“; 5.11.: „10te Stunde“; 9.11.: „14te Stunde“; 12.11.: „15te Stunde“; 16.11.: „19te Stunde“; 19.11.: „20te Stunde“; 21.11.: „22. Stunde“; 23.11.: „24. Stunde“; 26.11.: „25. Stunde“; 30.11.: „29.Stunde“; 3.12.: „30. Stunde“; 7.12.: „34. Stunde“; 10.12.: „35. Stunde“; 14.12.: „39. Stunde“; 17.12.: „40. Stunde“; 21.12.: „44. Stunde“. ${ }^{80}$ Im Tageskalender 1833 finden sich folgende Stunden notiert: 3.1.: „Alle Collegia mit 44ter Stunde angefangen.; 4.1.: „45. Stunde“; 7.1.: „46. „Stunde“; 11.1.: „50te Stunde“; 14.1.: „51. Stunde“; 18.1.: „55. Stunde“; 21.1.: „56. Stunde“; 24.1.: „Ausgesezt Kollegia“; 25.1.: „59. Stunde“; 28.1.: „60. Stunde“; 1.2.: „64. Stunde“; 2.2.: „Kollegia nachgeholt“; 4.2.: „65. Stunde“; 8.2.: „69. Stunde“; 11.2.: „Kollegia ausgesezt wegen des Begräbnisses der Generalin Braun“; 12.2.: „70. Stunde"; 15.2.: „73. Stunde Gartenkunst angefangen“; 18.2.: „74. Stunde“; 22.2.: „78. Stunde“; 25.2.: „79. Stunde“; 1.3.: „83. Stunde“; 4.3.: „84. Stunde“; 8.3.: „88. Stunde“; 11.3.: „89. Stunde“; 15.3.: „93. Stunde“; 18.3.: „94. Stunde“; 22.3.: „98. Stunde“; 25.3.: „Aesthetik 99“; 29.3.: „Aesthetik 103 [...] geschlossen. "81 Offenbar ist Schleiermacher bei der Zählung jedoch ein Fehler unterlaufen, wovon auch seine Marginalien zum Kolleg 1832/33 zeugen: Er zählt die gehaltene Doppelstunde vor Weihnachten nur einfach. Auch die durchgehende Stundenzählung der Nachschrift Schweizer 1832/33, die zuverlässig erscheint, ergibt eine Gesamtstundenanzabl von 104 Stunden. ${ }^{82}$

Vom Kolleg 1832/33 sind insgesamt fünf Vorlesungsnachschriften bekannt, von denen drei erhalten sind: jeweils eine von Alexander Schweizer, von Ernst Ludwig Theodor Henke und von Sigismund Stern. Lommatzsch lagen für seine Edition neben der Nachschrift des „Professor Schweizer" noch die der „Licentiaten Dr. Erbkam und Dr. George" vor. ${ }^{83}$ Von Wilhelm Heinrich Erbkam, der 1855 Professor für Kirchengeschichte an der Universität Königsberg wurde, und Johann Friedrich Leopold George, später Professor der Philosophie in Greifswald, der 1862 Schleiermachers Vorlesungen über die Psychologie im Rahmen der "Sämmtlichen Werke“ herausgab, konnten jedoch keine entsprechenden Dokumente aufgefunden werden.

Die grundlegende Dreiteilung seiner Ästhetik in historische Einleitung, allgemeinen spekulativen und besonderen Teil behält Schleiermacher im Kolleg 1832/33 bei, wobei die historische Einleitung einen

$80 \mathrm{Vgl}$. Schleiermacher: Tageskalender 1832, erarbeitet von Elisabeth Blumrich, in: schleiermacher digital (Anm. 3).

81 Vgl. Schleiermacher: Tageskalender 1833, erarbeitet von Elisabeth Blumrich, in: schleiermacher digital (Anm. 3).

82 Vgl. „Editorischer Bericht“ zu Schleiermachers „Marginalien 1832/33“ und zur „Nachschrift Schweizer 1832/33“.

83 Schleiermacher: Ästhetik, hg.v. Lommatzsch (Anm. 59), S. IX. 
deutlich größeren Umfang als in den beiden vorherigen Kollegien einnimmt. Schleiermacher behandelt nun neben antiken Ansätzen zu einer Kunsttheorie bei Platon und Aristoteles und der Ästhetik der Empfindsamkeit im Kontext von Baumgarten bis Sulzer auch zeitgenössische Positionen der Ästhetik von Kant, Fichte und Schelling bis Hegel. Im allgemeinen Teil sind einige terminologische Veränderungen und konzeptuelle Verschiebungen feststellbar, zu erwähnen ist etwa die Einfübrung des Begriffs des „unmittelbaren Selbstbewusstseins", das in seiner immanenten Dynamik nun den Ausgangspunkt der künstlerischen Praxis darstellt und damit die Bedeutungsdimensionen des Begriffs der Stimmung umfasst. Diese wird nun als eine vergängliche Bestimmtheit der geistigen Tätigkeit des Selbst bestimmt: „Z. B. eine Gemüthsstimmung ist ein unmittelbares Selbstbewußtseyn. Stimmung deutet eine Fortwirkung an, und nicht bloß momentan, doch irgend wann entstanden und irgend wann vorüber; ein bestimmter qualitativer Moment dem ein andrer vorausging und ein andrer folgen wird. "84 Das ethische Konzept des "Gesamtbewusstseins“, in dessen Kontext die „freie Produktivität" der Kunst ab 1832/33 gestellt wird, ersetzt zudem die systematische Funktion des Begriffs des „Kunsttriebs" als den allgemeinen Grund dieser Produktivität. Zwar hat es Schleiermacher nicht mehr geschafft, seine lange Zeit geplante Ethik fertigzustellen, zu deren wesentlichen Elementen er einige Akademieabhandlungen veröffentlichte; in der mit dem „Gesamtbewusstsein" fundierten sozialen, historischen und kulturellen Einbettung der künstlerischen Produktivität zeigt sich allerdings, dass er die ethische Fundierung der Ästhetik konsequent weitergeführt hat. Die Anordnung der einzelnen Künste verschiebt sich im Kolleg 1832/33 nur geringfügig: Die 1819 und 1825 im Rabmen der Architektur kurz erwähnte „schöne Gartenkunst“ wird 1832/33 als eine eigenständige Kunstform zwischen Architektur und Malerei verortet; damit folgt die Skulptur als letzte Form der bildenden Künste nicht mehr auf die Architektur, sondern auf die Malerei.

Die Überarbeitung seiner Ästhetik hat Schleiermacher offenbar nach der Fertigstellung der beiden Akademieabhandlungen „Über den Umfang des Begriffs der Kunst in Hinblick auf die Theorie derselben" von 1831 und 1832 vorgenommen, allein die dritte, unvollendete Abhandlung ist erst nach dem Ende der Vorlesung 1833 entstanden. Das

${ }^{84}$ Kolleg 1832/33, Nachschrift Schweizer, S. 575. 
belegen seine Materialien zur Ästhetik, in denen sich beginnend auf der Rückseite eines Zirkularbriefes vom 9. November 1833 vorbereitende Notizen für diese dritte Abhandlung befinden, die im Anhang dieses Bandes erstmals vollständig veröffentlicht werden.

\section{Ausgaben}

Die erste Ausgabe der Ästhetik Schleiermachers erschien im Rahmen der "Sämmtlichen Werke" Schleiermachers, die nach seinem Tod im Februar 1834 von einigen seiner Schüler und Freunde konstituiert wurde und zwischen 1834 und 1864 beim Georg Reimer Verlag erschienen ist. ${ }^{85}$ Die im Rahmen dieser Gesamtausgabe von Carl Lommatzsch herausgegebene Edition von Schleiermachers Ästhetik wurde 1842 veröffentlicht. ${ }^{86}$

Im Vorwort macht Carl Lommatzsch deutlich, dass Schleiermacher seine Ästhetik im Kolleg 1832/33 gegenüber den vorherigen Entwürfen verändert hatte; Lommatzsch betrachtet aber diese Fassung als ibre reifste und lebendigste Gestalt, weshalb er seiner Edition vor allem Nachschriften dieses Kollegs zugrunde gelegt hat. Das von ihm nicht dokumentierte Verfahren des Kompilierens der drei verwendeten Nachschriften von Schweizer, Erbkam und George führt allerdings zu einem unzuverlässigen Text, in dem nicht nachvollziehbar ist, welche Passagen aus welcher Nachschrift stammen und an welchen Stellen der Herausgeber möglicherweise selbst eingegriffen hat. ${ }^{87}$ Beim Vergleich mit der Nachschrift Schweizer hat sich allerdings herausgestellt, dass Lommatzsch diese mit hoher Wahrscheinlichkeit als Leittext seiner Edition verwendet hat. Nicht nur der inhaltliche Verlauf beider Texte ist weitgehend identisch, sondern auch ibr Wortlaut ist bis hin $z u$ den Formulierungen einzelner Sätze gleich, so dass die Erstellung einer Seitenkonkordanz für diese Ausgabe möglich war. Die wenigen Passagen, die nicht in der Nachschrift, sondern nur in der Edition vorkommen, stammen somit wahrscheinlich aus einer der beiden an-

$85 \mathrm{Vgl}$. Hans-Joachim Birkner: „Die Kritische Schleiermacher-Ausgabe zusammen mit ihren Vorläufern vorgestellt", in: ders.: Schleiermacher-Studien, eingeleitet $u$. hg. von Hermann Fischer, Berlin / New York 1996, S. 309-335, hier: 309.

86 Schleiermacher: Vorlesungen über die Aesthetik. Aus Schleiermachers handschriftlichem Nachlasse und aus nachgeschriebenen Heften, hg.v. Carl Lommatzsch, in: Friedrich Schleiermachers sämmtliche Werke, 3. Abt., 7. Bd., Berlin 1842.

87 Vgl. Schleiermacher: Ästhetik, hg.v. Lommatzsch (Anm. 86), S. IX. 
deren Nachschriften oder von Lommatzsch selbst; da die Nachschriften Erbkam und George verschollen sind, kann die Textgestalt der Edition nicht mehr eindeutig rekonstruiert werden.

Vor allem aber stellt die weitgehende Ausklammerung der eigenbändigen Manuskripte Schleiermachers - das ursprüngliche Kollegheft von 1819 gibt Lommatzsch nur auszugsweise in Fußnoten wieder - einen Mangel dieser Edition dar. Denn selbst wenn Schleiermachers Ästhetik von 1832/33 ibre reifste Ausführung sein sollte, könnte diese Einschätzung nur aufgrund eines Vergleichs mit Textzeugen der vorhergehenden Kollegien gewonnen und begründet werden; diese Möglichkeit bleibt dem Leser aber durch die eingeschränkte Textzengenauswahl verschlossen. Auch aus den ibm noch vorliegenden Nachschriften der Kollegien 1819 (Wigand) und 1825 (Braune und Bindemann) bringt Lommatzsch nur wenige ergänzende Auszüge aus der Behandlung der Poesie. ${ }^{88}$ Lommatzsch, der durch die Heirat mit Schleiermachers zweitältester Tochter Gertrud 1830 zum engeren Familienkreis hinzugetreten war, begründete seine Entscheidung auch damit, dass "Schleiermacher die Absicht hatte, die Aesthetik eigenhändig noch als selbstständiges Werk zu bearbeiten und herauszugeben [...], ungeachtet sich nichts handschriftlich Begonnenes darüber vorfindet" ${ }^{89}$ Ludwig Jonas, Schleiermachers Schüler und später der Verwalter von dessen wissenschaftlichem Nachlass, erwähnt in seinem Bericht über die letzten Tage Schleiermachers nur, dieser habe nichts gegen eine Veröffentlichung seiner Ästhetik gehabt, von einer Absicht Schleiermachers, die Ästhetik selbst als Buch herauszubringen, finden sich aber darin und auch sonst keine Hinweise. ${ }^{90}$

Im Jahr 1932 gab der bereits als Herausgeber von Schleiermachers Dialektik hervorgetretene Rudolf Odebrecht Schleiermachers Ästhetik erneut heraus. ${ }^{91}$ Odebrecht kritisiert einleitend die offenkundigen Mängel der Edition Lommatzsch und macht zudem geltend,

88 Schleiermacher: Ästhetik, hg.v. Lommatzsch (Anm. 86), S. 691-710.

89 Schleiermacher: Ästhetik, hg.v. Lommatzsch (Anm. 86), S. V.

90 Vgl. Nowak: Schleiermacher (Anm. 1), S. 458, der die neuere Fassung des Jonasschen Textes von Hans-Friedrich Traulsen zitiert: „Aus Schleiermachers letzten Tagen (25. Januar bis 12. Februar 1834) “, in: Zeitschrift für Kirchengeschichte 102 (1991), S. 372-385. Tobias Kirchbof: Der Tod Schleiermachers. Prozess und Motive, Nachfolge und Gedächtnis, Leipzig 2007.

91 Vgl. Friedrich Schleiermachers Ästhetik, im Auftrage der Preussischen Akademie der Wissenschaften und der Literatur-Archiv-Gesellschaft zu Berlin nach den bisher unveröffentlichten Urschriften, hg. v. Rudolf Odebrecht, Berlin 1931. 
dieser habe Schleiermachers Ästhetik durch die Konzentration auf das Kolleg 1832/33 verfälscht; er vergleicht Lommatzschs Edition darin mit der Hotho-Ausgabe von Hegels Ästhetik. ${ }^{92}$ Dabei kehrt Odebrecht das Kriterium der Textzengenauswabl von Lommatzsch geradezu um, indem er bemängelt, dass dessen Editionsprinzip auf Kosten von Schleiermachers eigenhändigen frühen Manuskripten gehe; zudem habe Schleiermacher selbst in seinem letzten Ästhetikkolleg seinen prägnanten Erstentwurf von 1819 aufgeschwemmt und verwirrt. ${ }^{93}$ Dementsprechend legt Odebrecht in seiner Edition ein Schwergewicht auf das Material von 1819, von dem er Schleiermachers Kollegheft ("Grundheft 1819 (A)“) und die Nachschrift Blubme in Auszügen wiedergibt, indem er beide Texte ineinander fügt, so dass Auszüge der Nachschrift ergänzend und in kleinerer Schrift zwischen die (nach einem fraglichen Verfahren fragmentierten) Passagen des Kollegheftes eingeschoben sind. Wobl aufgrund dieses Montageverfahrens musste Odebrecht einzelne Sätze des Kollegheftes umstellen und syntaktische Veränderungen vornehmen, die nicht dokumentiert sind, im Gegensatz zur erwähnten veränderten Zeichensetzung. ${ }^{94} \mathrm{Ab}$ schließend bringt Odebrecht auch einen Teil von Schleiermachers vorbereitenden Notizen zur Ästhetik („Reflexionen“) sowie die Randnotizen zum Kolleg 1832/33 heraus, womit erstmals fast alle bekannten Manuskripte Schleiermachers zu seinen Ästhetikvorlesungen veröffentlicht waren.

Die editorischen Mängel der Edition Odebrecht liegen neben einigen Febllesungen und nicht gekennzeichneten editorischen Eingriffen in der falschen Identifikation der anonymen Vorlesungsnachschrift des Jahrgangs 1825 als eines Autographs Schleiermachers. Obwobl er Abweichungen in Orthographie und Interpunktion gegenüber dem Kollegheft 1819 feststellt, im Schriftbild unübliche Durchstreichungen erkennt und die fehlende Stundenzählung bemerkt, bleibt Odebrecht bei dem Schluss, es handele sich um das Fragment eines Heftes Schleiermachers von 1825 („Heft B“), das eine Vorarbeit für eine geplante Publikation sein könne. ${ }^{95}$ In der Schleiermacherforschung wurde dieser Irrtum erst in den 1990er Jahren aufgeklärt. ${ }^{96}$

92 Schleiermacher: Ästhetik, hg.v. Odebrecht (Anm. 91), S. XXIV-XXV.

93 Schleiermacher: Ästhetik, hg.v. Odebrecht (Anm. 91), S. XIX, XXIV-XXV.

94 Einzelne Sätze sind umgestellt auf den Seiten 5-6, 7-8, 8-9, 40-41, 49-50, 54-55, 60-61, 139-140, 143-144.

95 Schleiermacher: Ästhetik, hg.v. Odebrecht (Anm. 91), S. XXX.

$96 \mathrm{Vgl}$. Andreas Arndt und Wolfgang Virmond: „Rez. Friedrich Daniel Ernst Schleiermacher: Ästhetik (1819/25). Über den Begriff der Kunst (1831/32), hg.v. Thomas 
Ergänzend zu diesem „Heft B“ bringt Odebrecht Auszüge aus der Nachschrift Bindemann 1825.

Im Jahr 1984 erschien eine Studienausgabe von Schleiermachers Ästhetik von Thomas Lehnerer. ${ }^{97}$ Diese reproduziert Odebrechts Edition von Schleiermachers „Grundheft 1819“ weitgehend, jedoch ohne die Einschiebung der Nachschrift Blubme und unter Rücknabme einiger syntaktischer Eingriffe. Statt den „Reflexionen“ und den Marginalien von 1832/33 enthält diese Ausgabe die drei Akademieabhandlungen Schleiermachers „Über den Begriff der Kunst“. Gleichwohl wiederholt Lehnerer die falsche Einschätzung Odebrechts bezüglich der anonymen Nachschrift 1825 und betrachtet sie trotz einiger Zweifel als ein Autograph Schleiermachers. ${ }^{98}$ Vorlesungsnachschriften entbält diese Ausgabe sonst keine.

Eine französische Ausgabe der Ästhetik Schleiermachers aus dem Jahr 2004 geht auf Vorarbeiten von Wolfgang Virmond zurück, insofern für die Übersetzung dessen Transkription von Schleiermachers Kollegheft 1819 herangezogen wurde; Auszüge aus der anonymen Nachschrift von 1825 sind ergänzend einbezogen. ${ }^{99}$

Eine weitere Studienausgabe brachte 2018 erstmals die wieder aufgefundene Nachschrift Schweizer von Schleiermachers Ästhetikkolleg 1832/33 vollständig heraus; die Ausgabe enthält zudem die drei Akademieabhandlungen Schleiermachers "Über den Begriff der Kunst". ${ }^{100}$

Die Akademieabhandlungen Schleiermachers mit dem vollständigen Titel „Über den Umfang des Begriffs der Kunst in Bezug auf die Theorie derselben" wurden zunächst in den "Sämmtlichen Werken" 1835 durch Ludwig Jonas veröffentlicht und erfubren ibre historischkritische Ausgabe im Rahmen der ersten Abteilung der KGA, im Band 11: „Akademievorträge“. ${ }^{101}$

Lehnerer, Hamburg 1984“, in: New Athenaeum / Neues Athenaeum 2, 1991, S. 190-196.

97 Schleiermacher: Ästhetik (1819/25). Über den Begriff der Kunst (1831/32), hg.v. Thomas Lehnerer, Hamburg 1984.

98 Schleiermacher: Ästhetik, hg.v. Lehnerer (Anm. 97), S. XVIII-XXI.

99 Schleiermacher: Esthétique. Tous les hommes sont des artistes, édité par Denis Thouard, traduction de l'allemand par Christian Berner, Élisabeth Décultot, Marc de Launay et Denis Thouard, introduction par Christian Berner et Denis Thouard, postface de Paolo d'Angelo, Paris 2004.

100 Schleiermacher: Ästhetik (1832/33). Über den Begriff der Kunst (1831-33), hg.v. Holden Kelm, Hamburg 2018.

101 Schleiermacher: Reden und Abhandlungen der Königlichen Akademie der Wissenschaften. Aus Schleiermachers handschriftlichem Nachlasse und aus nachgeschriebenen Heften, hg.v. Ludwig Jonas, in: Friedrich Schleiermachers sämmtliche 


\section{Rezeption}

Neben dem editorischen Verfahren verhinderte wobl auch die späte Herausgabe von Schleiermachers Ästhetik im Jahr 1842 ibre produktive Rezeption im ästhetischen Diskurs der klassischen deutschen Philosophie. Obwohl Schleiermacher auf der Höhe seiner Zeit argumentiert, auf die Positionen Kants, Schellings und Hegels teilweise konstruktiv Bezug nimmt, wurde seine Ästhetik im 19. Jahrhundert nur marginal wahrgenommen. Auch die Rezension von Wilhelm Danzel in der Neuen Jenaischen Allgemeinen Literatur-Zeitung aus dem Jahr 1844 führte offenbar nicht zu der vom Rezensenten gewünschten Breitenwirkung der Ästhetik Schleiermachers. ${ }^{102}$ Vor allem die mangelnde Konzentration und Bündelung der vielen eröffneten Fragen und Probleme gibt dem Rezensenten Anlass zur Kritik, wobei er diese Vielfalt zugleich als dem Gegenstand der Ästhetik angemessen bezeichnet und die Ausgabe insgesamt für bedeutsam hält. Weitere Besprechungen erfolgten erst in philosophiehistorischen Gesamtdarstellungen zur Ästhetik des 19. Jahrhunderts, in denen Schleiermachers Ästhetik meist in den Schatten der Hegelschen und Schellingschen Ästhetik gestellt wurde und mitunter polemische Reaktionen hervorrief. ${ }^{103}$ In der "Geschichte der deutschen Ästhetik seit Kant“ (1886) von Eduard von Hartmann wird Hegels und Schleiermachers Ästhetik etwa in Beziehung gesetzt, indem beide unter der Rubrik des ,konkreten Idealismus" diskutiert werden. Hartmann stellt dabei fest, dass Schleiermachers Ästhetik die Hegelsche in „psychologischer und erkenntnistheoretischer" Hinsicht ergänze, insofern letztere vor allem auf das Verhältnis der "Aesthetik zur Metaphysik" konzentriert sei. ${ }^{104}$ Dabei konnte sich Hartmann jedoch nicht enthalten, Schleiermachers Ästhetik in der Lommatzsch-Edition als einen "formlose[n]

Werke, 3. Abt, 3. Bd., Berlin 1835, S. 179-224. KGA I/11, S. 725-742, 769-786, 787-794.

102 Wilhelm Danzel: „Rez. Vorlesungen über die Aesthetik. Aus Schleiermachers handschriftlichem Nachlasse und aus nachgeschriebenen Heften, hg.v. Karl Lommatzsch, Berlin 1842", in: Neue Jenaische Allgemeine Literatur-Zeitung, 3. Jg., Nr. 40, 15. Februar 1844 sowie Nr. 41, 16. Februar 1844.

$103 \mathrm{Vgl}$. etwa Robert Zimmermann: Ästhetik, erster historisch-kritischer Teil, Wien 1858. Hermann Lotze: Geschichte der Ästhetik in Deutschland, viertes Buch, München 1868. Max Schasler: Kritische Geschichte der Aesthetik, Berlin 1872.

104 Eduard von Hartmann: Die deutsche Aesthetik seit Kant. Erster historisch-kritischer Theil, in: Eduard von Hartmanns Ausgewählte Werke, zweite Ausgabe, Bd. III, Aesthetik, Leipzig 1886, S. 157. 
Gedankenbrei, in welchem vieles Triviale, noch mehr Halbwabres und Schiefes und einige gute Bemerkungen durcheinander gerührt sind", zu bezeichnen. ${ }^{105}$ Hierbei reflektierte Hartmann jedoch nicht auf die Konzentration der Edition Lommatzschs auf das Kolleg 1832/33; auch die Akademieabhandlungen oder andere kunsttheoretische Schriften Schleiermachers berücksichtigte er nicht.

Wilhelm Dilthey brachte die Bedeutung von Schleiermachers Ästhetik ansatzweise zur Geltung, indem er sie in eine Reihe mit der von A. W. Schlegel, Schelling, Solger, Hegel und Schopenhauer stellt. Aber auch seine Auszeichnung Schleiermachers als dem „Ästhetiker der Romantik" änderte nicht viel an dessen geringer Präsenz im philosophisch-ästhetischen Diskurs, nicht zuletzt auch deshalb, weil Dilthey vor allem auf Schleiermachers Hermeneutik aufmerksam machte, die im 20. Jahrhundert eine breite Wirkung entfaltete. ${ }^{106}$ Auch die wohl durch Diltheys Arbeiten zu Schleiermacher mit ermöglichte Edition Odebrechts von 1931 beförderte ibre Diskussion nicht wesentlich, was wohl auch durch die historischen Umstände - den baldigen Ausbruch des Zweiten Weltkrieges und die damit einhergehenden Notlagen - bedingt sein dürfte. Eine Ausnahme in dieser Zeit bildet der italienische Philosoph Benedetto Croce: Seine Entdeckung der Ästhetik Schleiermachers stell eine konstruktive Fortsetzung einiger ibrer Grundgedanken dar, wovon schon der deutsche Titel seines ästhetischen Hauptwerks zeugt: „Aesthetik als Wissenschaft des Ausdrucks und allgemeine Linguistik" (1905). ${ }^{107}$ Auch in Frankreich machte Croce Schleiermachers Ästhetik bekannt: Er veröffentlichte 1934 einen Artikel über sie in der "Revue de métaphysique et de morale“freilich in einem Kontext, in dem bereits Hegels „Phänomenologie des Geistes" und die „Pariser Manuskripte" von Karl Marx eine breite Aufmerksamkeit auf sich zogen. ${ }^{108}$

105 Hartmann: Die deutsche Aesthetik seit Kant (Anm. 104), S. 156.

106 Wilhelm Dilthey: Leben Schleiermachers, 2. Bd., Schleiermachers System als Philosophie und Theologie, aus dem Nachlass von W. Dilthey, hg.v. Martin Redeker, Göttingen 1966, S. 443.

107 Benedetto Croce: Aesthetik als Wissenschaft des Ausdrucks und allgemeine Linguistik. Theorie und Geschichte, aus dem Italienischen übersetzt von Karl Federn, Leipzig 1905.

108 Benedetto Croce: „L'esthétique de Schleiermacher", in: Revue de métaphysique et de morale, Nr. 41, 1934, S. 327-341. - Eine weitere Rezeptionslinie führt zu Edgar Wind, einem Schüler von Aby Warburg, der jedoch primär auf Schleiermachers Akademieabhandlung „Über den Umfang des Begriffs der Kunst" rekurriert. Vgl. Edgar Wind: "Warburgs Begriff der Kulturwissenschaft und seine Bedeutung für die Ästhetik", in: Zeitschrift für Ästhetik und allgemeine Kunstwissenschaft 25 (Beibeft), Stuttgart 1931, S. 163-179. 
In der Nachkriegszeit erneuerte Hans-Georg Gadamer die Diskussion über Schleiermachers Hermeneutik; Schleiermachers Ästhetik blieb dabei weitgehend unberücksichtigt, zumindest solange, bis die literaturwissenschaftliche und philosophische Forschung die Frübromantik (wieder-)entdeckte und mit ibrer kritischen Aufarbeitung, etwa in Form von historisch-kritischen Gesamtaugaben begann. ${ }^{109}$ In der Folge entstanden auch neue Interpretationen und kritische Aufarbeitungen von Schleiermachers Ästhetik, etwa in Hinblick auf ihre Musikphilosophie (Scholtz 1981), auf ihre Stellung in Schleiermachers philosophisch-theologischem System (Lehnerer 1987) oder hinsichtlich ibres frübromantischen Kontextes (Käfer 2006). Bis auf einige Ausnahmen, wie die Beiträge über Schleiermachers Ästhetik für den Internationalen Kongress der Schleiermacher-Gesellschaft von 2015 „Der Mensch und seine Seele. Bildung - Frömmigkeit - Ästhetik“ belegen, ist Schleiermachers Philosophie der Kunst bis heute eher ein Randphänomen des ästhetischen Diskurses geblieben. ${ }^{110}$

\section{Editorischer Bericht}

\section{Erster Teil. Manuskripte Schleiermachers}

Sämtliche bekannten Manuskripte Schleiermachers zur Ästhetik befinden sich im Schleiermacher-Nachlass (SN) des Archivs der BerlinBrandenburgischen Akademie der Wissenschaften (ABBAW) und tragen noch den Stempelabdruck vom "Litteratur-Archiv" Berlin. Sie enthalten Exzerpte, Aphorismen und Notizen, die Schleiermacher vor und während seiner Vorlesung 1819 verfasste sowie ein Kollegheft, das er für alle drei Kollegien verwendete und mit zum Teil umfangreichen Marginalien versehen hat. Diese Dokumente werden im Ersten Teil dieser Ausgabe wiedergegeben. - Außer diesen Dokumenten und teilweise mit ihnen zusammen archiviert, sind verschiedene Notizen überliefert, die nicht in direktem Zusammenhang mit Schleiermachers Ästhetikvorlesungen stehen, aber dennoch ästhetische Gegenstände

109 Vgl. etwa die historisch-kritischen Gesamtausgaben der Werke von Friedrich Schlegel oder die von seinem Bruder August Wilhelm Schlegel, die Ernst Behler u. a. auf den Weg brachten.

110 Arnulf von Scheliha und Jörg Dierken (Hg.): Der Mensch und seine Seele. BildungFrömmigkeit - Ästhetik, Akten des Internationalen Kongresses der SchleiermacherGesellschaft in Münster, September 2015, Berlin/Boston 2017. 
behandeln, darunter befinden sich etwa ein Heft zur Musik oder auch Vorbereitungen Schleiermachers für seine dritte Akademieabhandlung „Über den Umfang des Begriffs der Kunst“. Ergänzend zu den in den editorischen Richtlinien der II. Abteilung (Einleitung der Herausgeber, III. 2.) genannten Textsorten werden diese Dokumente im Anhang dieses Bandes präsentiert, weil sie thematisch relevant sind und bisher noch nicht in historisch-kritischer Edition vorliegen. Die Edition dieser Texte folgt dabei den Richtlinien für die Vorlesungsmanuskripte Schleiermachers.

\section{Notizen zur Ästhetik I}

Unveröffentliches Manuskript: ABBAW, SN 110.

Es handelt sich um Notizen, die Schleiermacher für die Vorbereitung und die Durchführung seines Kollegs 1819 angefertigt hat. Darunter befinden sich kommentierte Exzerpte zu Schellings Rede „Über das Verhältnis der bildenden Künste zu der Natur" sowie Aphorismen über allgemeine Gesichtspunkte der Ästhetik und die einzelnen Künste, die teilweise in das Kollegheft 1819 eingegangen sind, wovon verschiedene Bearbeitungsvermerke zengen. Zudem finden sich hier anhängend Schleiermachers Vorbereitungen für seine dritte Akademieabhandlung „Über den Umfang des Begriffs der Kunst“.

Das Manuskript umfasst 4 halbe Bogen, d.h. 8 Blätter im Quartformat und einen Zettel. Die Seiten wurden nachträglich wohl von Archivseite mit Bleistift paginiert und enthalten einen für Schleiermachers Manuskripte typischen Rand von etwa 1/3 Seitenbreite für Ergänzungen. Die Bogen bestehen aus verschiedenen Papiersorten und hängen offenbar falsch zusammen; vieles deutet darauf hin, dass die jetzige Zusammensetzung nachträglich erfolgte, wenngleich nicht ausgeschlossen werden kann, dass Schleiermacher selbst eine gewisse Willkür bei der Papierwahl und der hinterlassenen Anordnung der Bogen walten ließ, zumal er nur wenig Zeit hatte, sein Ästhetikkolleg 1819 vorzubereiten. Odebrecht hat diese Notizen I erst nach der Veröffentlichung seiner Edition entdeckt und betrachtet sie fälschlich ausschließlich als „Vorarbeiten zur letzten Akademierede über Ästhetik". ${ }^{111}$ Das im vorliegenden Band als "Notizen zur Ästhetik II"

111 Odebrecht: Schleiermachers System der Ästhetik. Grundlegung und problemgeschichtliche Sendung, Berlin 1932, Vorwort: „Bei einer ungestörten Durchsicht der Schleiermacher-Archivalien fanden sich an entlegener Stelle noch einige Quartbogen mit Bemerkungen zur Ästhetik." 
edierte Heft hat Odebrecht hingegen als „Reflexionen“ zum Kolleg 1819 herausgegeben, was darauf hindeutet, dass die Notizsammlungen I und II bereits vor ibrer Sichtung durch Odebrecht, möglicherweise von Dilthey, in der jetzigen Form hinterlassen wurden. Lommatzsch berichtet nur am Rande von "Zettelchen zum Behuf der frühern ästhetischen Vorlesungen“, die sich in „ziemlich vollständigem Zusammenhange" vorfinden, womit unklar bleibt, wie die Vorlesungsnotizen ursprünglich zusammenhingen. ${ }^{112}$

Die Notizen der Bogen sind von Schleiermacher mit Eisengallustinte beschrieben. ${ }^{113}$ Der Bogen 1 (Seiten 1-2, 7-8) trägt auf der ersten Seite die Überschrift „Zur Aesthetik“, links darüber ist ein roter Stempelabdruck vom „Litteraturarchiv-Berlin“, der auch auf Seite 9 $z u$ finden ist. Der Bogen besteht aus hellem Papier, die Ränder weisen deutliche Abnutzungserscheinungen auf, sind angegilbt und teilweise eingerissen. Der Bogen 2 (Seiten 3-4, 5-6) ist in Bogen 1 eingelegt, besteht aus dunklerem Papier als dieser und enthält das Wasserzeichen "Spechthausen“. Bogen 3 (Seiten 9-10, 11-12) liegt unter den Bogen 1 und 2 und war ursprünglich wohl umgekehrt gefaltet, er besteht aus dem gleichen Papier wie Bogen 2, worauf auch der Schrifttyp des Wasserzeichens "I. W. Ebart" hindeutet. ${ }^{114}$ Der Text auf Seite 10 bricht nach 7 Zeilen ab. - Diese drei Bogen enthalten in loser Reihenfolge kommentierte Exzerpte, Aphorismen und Reflexionen Schleiermachers, die der Vorbereitung und Durchführung seines Ästhetikkollegs 1819 zugerechnet werden können, wovon die Erledigungsvermerke sowie Verweise auf die Vorlesungsstunden IV, VII, VIII und IX zengen, die im Textapparat nachgewiesen werden. Nicht nachgewiesen werden die für Schleiermachers Manuskripte typischen größeren Spatien, die im Drucktext durch größere Lücken dargestellt werden.

Der Zettel (S. 13-14) ist nur halb so breit wie die Bogen, enthält kein Wasserzeichen und ist bis zum unteren Rand beschrieben. Schleiermacher zerschnitt offenbar einen Zirkularbrief, der auf der Rückseite (S. 14) fragmentarisch erhalten ist, mit dem Datum „9.11.1833“

112 Schleiermacher: Ästhetik, hg.v. Lommatzsch (Anm. 86), S. VI.

$113 \mathrm{Vgl}$. Röntgenfluoreszenzanalyse der Schreibmaterialien Friedrich Schleiermachers, in: KGA II/12, hg.v. Jens Beljan, Christiane Ehrhardt, Dorothea Meier, Wolfgang Virmond, und Michael Winkler, Berlin/Boston 2017, Anhang, S. 892.

${ }^{114}$ Es handelt sich offenbar um handgeschöpftes imprägniertes Papier, das in der Papierfabrik Spechthausen bei Eberswalde (geführt von Johann Wilhelm Ebart und Söhnen) hergestellt wurde. 
und seiner Unterschrift versehen ist. Der Bogen 4 (Seiten 15-16, 1718) liegt unter dem Zettel und besteht aus dunklerem und festerem Papier wie Bogen 2 und 3 und enthält kein Wasserzeichen; auf Seite 17 ist nur der rechte Rand beschrieben. - Auf dem Zettel beginnen Notizen, die eindeutig der Vorbereitung von Schleiermachers dritter Akademieabhandlung „Über den Umfang des Begriffs der Kunst in Bezug auf die Theorie derselben" zugeschrieben werden konnten; auf Bogen 4 werden diese vorbereitenden Notizen fortgesetzt.

Entsprechend diesem Befund und den erkennbaren inhaltlichen Zusammenhängen wurden die Notizen umgestellt und in unterschiedliche zeitliche Schichten separiert: Bogen 1-3 werden als "Notizen zur Ästhetik I" dem Kolleg 1819, der Zettel und der darauffolgende Bogen 4 hingegen den "Notizen zur dritten Akademieabhandlung " zugeordnet; letztere werden im Anhang wiedergegeben.

Weil die einzelnen, mitunter kurzen und nicht über Seitenwechsel verlaufenden „Notizen zur Ästhetik I“ nicht nummeriert sind, keine in sich geschlossene Folge bilden und durch Trennungsstriche voneinander abgesetzt sind, mussten für ibre Anordnung neben den Materialmerkmalen der Bogen inhaltliche Gesichtspunkte herangezogen werden. Als Muster wurde der Verlauf des Kolleghefts 1819 zugrunde gelegt, das sich nach der kurzen Einleitung in einen allgemeinen und einen besonderen Teil gliedert, wobei zu berücksichtigen war, dass Schleiermachers Notizen diesem Muster nicht folgen müssen, weil sie mitunter auch spontane Einfälle wiedergeben. Dabei hat sich der folgende Zusammenhang der Bogen als plausibel erwiesen: Bogen 1 bildet den Umschlag, Bogen 3 folgt, jedoch umgekehrt gefaltet als vorliegend, und in diesem liegt Bogen 2, so dass sich die Seitenfolge ergibt: 1-2, 11-12, 3-4, 5-6, 9-10, 7-8.

Die Notizen beginnen auf den ersten beiden Seiten mit zum Teil aphoristisch formulierten Kommentaren und Exzerpten zu Schellings Rede „Über das Verhältnis der bildenden Künste zu der Natur", die 1807 veröffentlicht wurde. Schleiermacher exzerpiert diese Rede aufgrund der von ihm verwendeten Ausgabe der „Philosophischen Schriften" Schellings von 1809 mit Seitenangaben stellenweise wortwörtlich. ${ }^{115}$ Schleiermacher wurde spätestens durch August Boeckh auf diese Rede aufmerksam, der in zwei Briefen 1808 und 1809 mit

115 F. W.J. Schelling: „Ueber das Verhältniß der bildenden Künste zu der Natur“ (1807), Rede zum Anlass des Namensfestes des Bayrischen Königs am 12.10.1807, in: ders.: Philosophische Schriften, Bd. 1, Landshut 1809, S. 341-396. 
der Bitte an ihn herantrat, eine Rezension von ibr zu verfassen. ${ }^{116}$ Damit wäre als frühester Zeitpunkt für die Abfassung dieser Notizen das Jahr 1809 möglich. Da aber keine weiteren Hinweise auf eine geplante Rezension dieser Rede vorliegen, ist die Annabme wahrscheinlicher, dass Schleiermacher die Exzerpte erst anfertigte, als er sein erstes Ästhetikkolleg plante und sich eben dafür sein Heft „Zur Aesthetik" angelegt hatte. Das könnte bereits zum Jahresende 1816 gewesen sein, als Schleiermacher an Gaß schrieb, ihm fehlten in seiner Lehre noch ganze Disziplinen, darunter auch die „Aesthetik“. ${ }^{117}$ Spätestens zum Jahresende 1818 dürfte Schleiermacher an der Verwirklichung seines Planes gearbeitet haben, er schrieb an Brinckmann: „im nächsten Jahr denke ich an die Aesthetik zu gehn. "118 Allerdings teilte Schleiermacher Twesten noch gut fünf Wochen vor Vorlesungsbeginn mit, er plane ein Kolleg, das er „schon lange im Schilde fübre, aber wozu noch nichts vorbereitet ist, nämlich Aesthetik. "119 Zwar könnte der erste Teil dieser Mitteilung auch so gedeutet werden, dass Schleiermacher bereits seit längerer Zeit Notizen zur Ästhetik führte, er könnte aber auch auf den bereits im Rabmen der Ethik entworfenen Grundriss der Ästhetik deuten. Da Schleiermacher jedoch angibt, „noch nichts vorbereitet" zu haben, ist es wahrscheinlicher, dass er diese Exzerpte erst in den gut fünf Wochen vor Vorlesungsbeginn am 19. April 1819 niederschrieb. Weil Schleiermacher bei der Besprechung der Kunstschönheit in seinem Kollegheft (26. Stunde, 27. Mai) auf einen Passus der Rede Schellings rekurriert, müssten diese Exzerpte spätestens vor dieser Stunde entstanden sein.

Die an diese Exzerpte anschließenden Notizen dürften teils in die engere, gut fünfwöchige Vorbereitungszeit, teils in die Zeit der Durchführung des Kollegs fallen. Sie enthalten überwiegend allgemeine Überlegungen zur Anlage und Konzeption der Ästhetik, die der Abhandlung des Kolleghefts inhaltlich und teilweise auch dem Wortlaut nach entsprechen. Allerdings finden einige Gedanken über die Malerei und die Poesie (etwa auf S. 7-8) keine Entsprechung im Kollegheft

116 Vgl. Briefe von A. Boeckh an F. Schleiermacher vom 7. Oktober 1808 und vom 5. April 1809: Brief 2859, KGA V/10, S. 286 und Brief 3193, KGA V/11, S. 225.

117 Brief von F. Schleiermacher an Joachim Christian Gaß, vom 29. Dezember 1816 bis 2. Januar 1817, in: Schleiermachers Briefwechsel mit J. Chr. Gaß (Anm. 46), S. 128.

118 Brief von F. Schleiermacher an C. G. v. Brinckmann vom 31. Dezember 1818, in: Aus Schleiermachers Leben (Anm. 47), S. 241.

119 Brief von F. Schleiermacher an August D. C. Twesten vom 14. März 1819, in: D. August Twesten nach Tagebüchern und Briefen (Anm. 51), S. 342. 
1819, da es bei der Behandlung der Skulptur abbricht. Wie die Erledigungsvermerke und die Verweise auf Vorlesungsstunden belegen, führte Schleiermacher seine Notizen I zeitweise parallel zu seinem Kollegheft. Dabei ist es auch möglich, dass er einige Notizen erst nach der Abhaltung einzelner Stunden verfasste, wie es etwa auch bei seinen Dialektik- oder Psychologievorlesungen der Fall ist. Der wahrscheinliche Zeitpunkt, zu dem er die Notizen I abgeschlossen haben dürfte, ist das Ende der Vorlesung am 7. August 1819. Da im Kollegheft 1819 die Behandlung der Malerei und Poesie fehlen, ist nicht auszuschließen, dass Schleiermacher für den Abschluss seines Kollegs 1819 auf diese Notizen zurückgriff und sie eventuell auch für den Abschluss des Kollegs 1825 verwendete.

\section{Notizen zur Ästhetik II}

Manuskript: ABBAW, SN 112/2. ${ }^{120}$ Erstveröffentlichung und Seitenkonkordanz: Edition Odebrecht (ÄOd). ${ }^{121}$

Es handelt sich um ein Notizheft, das Schleiermacher für die Vorbereitung und Durchführung seines Kollegs 1819 angefertigt und verwendet hat. Odebrecht brachte dieses Notizheft unter dem Titel „Reflexionen" heraus und charaktisierte die Notizen als Einfälle und Zusätze zum Kollegheft 1819. Die Notizen enthalten neben Exzerpten zu Schellings Vorlesungen über die Philosophie der Kunst überwiegend Aphorismen zum besonderen Teil über die einzelnen Künste. Einzelne Verweise auf Vorlesungsstunden und die für Schleiermacher üblichen Bearbeitungsvermerke verdeutlichen einen den Notizen I ähnelnden Charakter dieses Notizheftes als einer Materialsammlung für seine Kollegien.

Das Manuskript besteht aus 3 halben Bogen, d.h. 6 Blättern im Quartformat, die zu einem Heft gefaltet sind und einem Zettel. Das Heft ist von Archivseite durchgehend mit Bleistift paginiert und bis auf die letzten drei Seiten (10-12) beidseitig beschrieben. Zwischen die Seiten 4 und 5 wurde offenbar nachträglich ein Zettel eingefügt, der die Seitennummer 3 a trägt; er enthält Notizen zu Bouterweks Äs-

120 Unter der Signatur 112/1 wird in dieser Mappe auch Schleiermachers Manuskript zur „Würdigung des Fürsten Radziwill“ (1833) aufbewahrt, das bereits veröffentlicht ist in: KGA I/14, hg.v. Hermann Fischer, Ulrich Barth, Konrad Cramer, Günter Meckenstock, Kurt-Victor Selge, Berlin / New York 2003, S. 363-368.

121 Schleiermacher: Ästhetik, hg.v. Odebrecht (Anm. 91), S. 318-327. 
thetik (1815) und steht inhaltlich in keinem direkten Zusammenhang mit den Kollegien, weshalb er im Anhang dieses Bandes wiedergegeben wird. ${ }^{122}$ Das Papier der drei Bogen ist mit Eisengallustinte beschrieben, die Seiten haben den für Schleiermacher typischen Rand von etwa 1/3 Seitenbreite, die Notizen und Aphorismen sind durch Trennstriche voneinander abgesetzt. Die Kanten der Blätter sind teilweise ausgefranst und die Ränder leicht vergilbt. Die Bogen hängen wie folgt zusammen: Bogen 1: Seiten 1-2, 11-12; Bogen 2: Seiten 34, 9-10; Bogen 3: Seiten 5-6, 7-8. Auf Seite 1 beginnen die Notizen ohne Überschrift mit der Sentenz: „Musik: Rhythmus Melodie Harmonie."

Die unveränderte Faltung, die einheitliche Papiersorte und die drei leeren Seiten am Ende des Heftes vermitteln den Eindruck, dass es in seiner ursprünglichen Anlage erhalten ist. Da die Bogen 1-3 offenbar aus derselben Papiersorte wie der Bogen 1 der Notizen I („Zur Aesthetik“) bestehen, könnte es sein, dass diese Bogen ursprünglich zusammenhingen. Es lässt sich jener Bogen 1 aber nicht sinnvoll etwa als Umschlagbogen den Notizen II anfügen, seine beschriebenen Seiten 7 und 8 würden dann auf drei leere Seiten folgen, auch weist sein verschlissener Zustand auf eine unterschiedliche Verwendung oder frühzeitige Entnahme aus diesem Heft hin. Die leeren Seiten am Ende des Heftes der Notizen II belegen zudem, dass Schleiermacher die Arbeit an ihm beendete, bevor ihm der Platz zum Weiterschreiben ausging. Dieser Befund und die bündige Anlage des Heftes sprachen dafür, es als zweiten Teil von Schleiermachers Vorlesungsnotizen zur Ästhetik zu behandeln.

In den Notizen setzt sich Schleiermacher zunächst wiederum mit Schellings Kunstphilosophie auseinander; wie Odebrecht bereits festgestellt hat, muss es sich dabei um Schellings „Vorlesungen über die Philosophie der Kunst" handeln, die dieser 1802/03 in Jena gehalten und 1804/05 in Würzburg wiederholt hat. ${ }^{123}$ Allerdings sind diese Vorlesungen erst posthum, in den "Sämmtlichen Werken" Schellings 1859 von seinem Sohn veröffentlicht worden. ${ }^{124}$ Schleiermacher hätte für diese Notizen also über eine Nachschrift des Jenaer oder Würzbur-

122 Vgl. unten „Editorischer Bericht“ zu „Notiz zur Ästhetik von Bouterwek“.

123 Schleiermacher: Ästhetik, hg.v. Odebrecht (Anm. 91), S. XXXI.

124 Schelling: Vorlesungen über die Philosophie der Kunst, in: Friedrich Wilhelm Joseph von Schellings sämmtliche Werke, hg.v. Karl Friedrich August Schelling, Abt.I, Bd. 5, Stuttgart und Augsburg 1859. 
ger Kollegs verfügen müssen, von einer solchen finden sich allerdings keine Spuren in seinem Nachlass. In der historisch-kritischen Ausgabe der Kunstphilosophie Schellings ist die Nachschrift Schlosser des Kollegs 1802/03 enthalten, auf die einige der Notizen Schleiermachers inhaltlich bezogen werden können. ${ }^{125}$ Schleiermacher rekurriert etwa auf Schellings Einteilung der bildenden Künste in die drei Stufen Musik, Malerei und Plastik sowie die Unterteilung der Plastik in Architektur, Basrelief und Skulptur, er hinterfragt die "Schellingsche Parallelisierung von Architectur und Musik", referiert dessen Ansicht, die plastische Kunst stelle den Gipfel der bildenden Kunst dar und reflektiert Schellings Deduktion der Plastik aus der Malerei. ${ }^{126}$ Aus den ihm nachweislich bekannten Texten Schellings hätte Schleiermacher diese detaillierten Kenntnisse nicht entnehmen können. Von einer Nachschrift des Typs Schlosser, die möglicherweise von Schelling autorisiert worden war, waren wahrscheinlich mehrere im Umlauf und es ist wahrscheinlich, dass auch Schleiermacher eine solche zur Verfügung stand, die dann später möglicherweise aus seinem Nachlass ausgesondert wurde. Eine solche Nachschrift besaßen etwa Dorothea und Friedrich Schlegel, von denen sie sich Schleiermacher auch geliehen haben könnte, wovon sich jedoch keine Hinweise finden; Friedrich Ast und Solger kannten die Vorlesungen Schellings auch. ${ }^{127}$ Wie und wann Schleiermacher diese Kenntnisse erlangt haben könnte, ist somit nicht mehr feststellbar - auch seine 1803 erschienene Rezension von Schellings „Vorlesungen über die Methode des akdemischen Studium" bietet keine weiteren Anhaltspunkte. ${ }^{128}$ Da Schleiermacher in seinem Kollegheft 1819, im Rahmen der Einteilung der Künste in der 37. Vorlesungsstunde, Schellings Einordnung der Musik unter die bildenden Künste erörtert, ist es wahrscheinlich, dass er diese Notizen spätestens zu dieser Stunde niedergeschrieben hatte, die um den 17. Juni datiert werden kann.

In den weiteren Notizen kommentiert Schleiermacher kunsttheoretische Aussagen Goethes, Diderots und Friedrich Asts und behandelt weniger allgemeine Gesichtspunkte der Ästhetik, wie in den Notizen I, sondern überwiegend spezifische Bestimmungen und Ver-

125 Schelling: Philosophie der Kunst und weitere Schriften (Anm. 25), S. 18.

$126 \mathrm{Vgl}$. unten „Notizen zur Ästhetik II“, S. 23.

127 Vgl. Schelling: Philosophie der Kunst und weitere Schriften (Anm. 25), S. 78-81.

128 Schleiermacher: Rezension von Friedrich Wilhelm Joseph Schelling: Vorlesungen über die Methode des akademischen Studiums, KGA I/4, hg.v. Eilert Herms, Günter Meckenstock und Michael Pietsch, Berlin / New York 2002, S. 461-484. 
hältnisse der einzelnen Künste, die mit dem besonderen Teil des Kolleghefts korrespondieren; darunter befinden sich aber auch zwei Verweise auf die Einleitung und einer auf die 8. Vorlesungsstunde. Die inhaltliche Ausrichtung der Notizen I und II ist somit zwar tendenziell unterschiedlich, sie erlaubt aber nicht die Feststellung eines eindeutigen zeitlichen Nacheinanders beider Hefte, vielmehr scheint Schleiermacher sie zeitweise auch parallel geführt zu haben. Somit dürften die Notizen II größtenteils in einer ähnlichen Zeit wie die Notizen I entstanden sein; wahrscheinlich ist die Zeitspanne zwischen der etwa fünfwöchigen Vorbereitungszeit und dem Ende des Kollegs. Es ist auch bei diesen Notizen denkbar, dass Schleiermacher die Reflexionen über Malerei und Poesie nutzte, um seine Kollegien 1819 und 1825 abzuschließen, da das Kollegheft selbst bereits bei der Skulptur abbricht.

\section{Kollegheft Ästhetik 1819}

Manuskript: ABBAW, SN 109. Erstveröffentlichung und Seitenkonkordanz: Edition Odebrecht (ÄOd).

Das Kollegheft enthält Schleiermachers grundlegende Abhandlung zur Ästhetik, die er für das Kolleg 1819 angefertigt hat und für die Durchführung aller drei Kollegien verwendete. Für das Kolleg 1825 notierte er darin einige wenige, für das von 1832/33 umfangreiche, die ursprüngliche Konzeption teilweise erweiternde Marginalien. Die Abhandlung beginnt auf dem Titelblatt mit der Überschrift „Aesthetik". Nach einer kurzen Einleitung folgt der allgemeine Teil über die philosophisch-ethischen Grundlagen der Ästhetik, an den der besondere Teil über die einzelnen Künste Mimik, Musik, Architektur und Skulptur anschließt, danach bricht das Manuskript ab. Odebrecht veröffentlichte das Kollegheft 1819 als „Grundheft 1819 (A)“ mit einer Reihe von Ergänzungen und Umstellungen.

Das Manuskript besteht aus 23 einzeln übereinander liegenden halben Bogen, d.h. 46 Blättern im Quartformat; von den 92 sind 91 Seiten beschrieben. Das Papier ist offenbar das gleiche, wie das der 3 Bogen der Notizen II und an den Ecken leicht vergilbt. Die Seiten haben den für Schleiermacher typischen Rand von etwa 1/3 Seitenbreite für Nachträge, die Ränder sind abgegriffen und teilweise eingerissen, was auf eine mehrfache Benutzung schließen lässt. Die Bogen 
wurden offenbar von Schleiermacher am oberen rechten Rand nummeriert, die Seiten nachträglich (bisweilen aussetzend) am unteren Rand mit Bleistift paginiert. Die Bogennummern sind mit der gleichen Tinte (Eisengallustinte) geschrieben wie die gesamte Abhandlung. Am rechten Rand sind die Anfangsdaten der ersten beiden Kollegien notiert: „angef. 1819, d. 19. April" und „angef. 1825, d. 11. April“. Im Verlauf des Heftes sind die einzelnen Stunden mit römischen Ziffern gekennzeichnet, bis zur 42. Stunde im Haupttext und von der 43. bis zur 64. Stunde am Seitenrand. Aufgrund der sporadischen Datumsangaben der sekundär überlieferten Nachschrift Blubme konnten einige dieser Vorlesungsstunden datiert werden.

Am rechten Rand der Titelseite beginnen die Marginalien Schleiermachers, von denen einige dem Kolleg 1819 angehören (spontane Korrekturen oder Einfügungen), einige dem Kolleg 1825 (nachträgliche Ergänzungen oder Präzisionen). Die Marginalien 1825 werden im Textapparat nachgewiesen und fallen größtenteils in den besonderen Teil der Abhandlung. Die Marginalien zum Kolleg 1832/33 weisen eine eigene Stundenzählung auf und sind eindeutig vom Haupttext abgegrenzt; darüber hinaus lassen sie eine in sich geschlossene Abhandlung mit konzeptionellen Umgestaltungen erkennen, weshalb sie als ein eigenes Dokument wiedergegeben werden. ${ }^{129}$

Das Heft bricht auf Seite 91 in der 64. Stunde ab; die Seite ist zu etwa 5/6 beschrieben, die folgende Seite 92 ist leer und bildet den Abschluss des erhaltenen Heftes. Im Vergleich zur Systematik der einzelnen Künste in den Kollegnachschriften 1825 fehlen hier daher noch ein Restteil zur Skulptur sowie die Behandlung der Malerei und der Poesie. Bereits Lommatzsch lag das Heft in dieser Gestalt vor, er spricht, ohne mögliche Ursachen zu erwägen, von der „Unvollständigkeit des ursprünglichen Heftes", in dem der Schluss fehle, namentlich die Teile über Malerei und Poesie. ${ }^{130}$ Dass dieser Abbruch nicht durch Krankheit oder Reisen bedingt sein kann, ist dadurch belegt, dass Schleiermacher sein Kolleg offiziell bis zum 7. August 1819 gehalten hat und es damit, wie auch das parallel gehaltene Kolleg über Hermeneutik und Kritik, wie geplant zum Semesterende abschloss. Dafür spricht auch, dass in Lommatzschs Edition ein Auszug des Kapitels über die Poesie aus der Nachschrift Wigand 1819 überliefert ist, die in der Systematik der einzelnen Künste das Ende bildet. Wenn

129 Vgl. „Editorischer Bericht“ zu den „Marginalien zum Kolleg 1832/33“.

130 Schleiermacher: Ästhetik, hg.v. Lommatzsch (Anm. 86), S. VII. 
von den im Lektionskatalog angeführten fünf wöchentlichen Stunden ausgegangen wird, die letzte in der Nachschrift Blubme mitgeteilte 54. Stunde am 13. Juli stattfand und Schleiermacher das Kolleg tatsächlich am 7. August (einem Samstag) beendete, dann ist das Kolleg über 73 Stunden verlaufen und es fehlten ab der 64. Stunde Ausführungen zu ca. 9 Vorlesungsstunden bzw. ca. 2 Vorlesungswochen.

Am unteren rechten Rand der Seite 91 findet sich ein wobl von Schleiermacher selbst notiertes, schwer zu deutendes Zeichen: Es könnte ein „M“ mit darunter befindlichem Punkt bzw. Tintenklecks oder eine bloße Schreibprobe sein, die Schleiermacher durchführte, um die angespitzte und mit frischer Tinte versehene Feder zu testen. Als „M“ könnte das Zeichen ein Hinweis auf das Ende des Manuskripts sein, was bedeuten könnte, dass Schleiermacher im Sommer 1819 keine Zeit mehr zur Fortführung und Vollendung des Heftes fand und den Rest des Kollegs frei oder aufgrund der vorbereiteten Notizen beendet hatte. Wie sein Brief an Gaß nahe legt, führte Schleiermacher sein Kollegheft sukzessive und hatte es am 2. Juni, also etwa nach einem Drittel des Semesters, noch nicht fertig gestellt: „Meine Aesthetik gefällt mir bis jezt nicht übel aber ich weiß noch nicht wie ich fertig werden soll. "131 Die arbeitsintensiven wissenschaftlichen Projekte, die Schleiermacher außerhalb der Lehre beschäftigten, vor allem die Niederschrift seiner Ethik und Dogmatik, könnten die Annabme eines wegen Zeitmangels unvollendet gebliebenen Heftes bekräftigen. Zudem ist es nicht unüblich, dass ein Vorlesungsmanuskript Schleiermachers nicht bis zum Ende des Semesters reicht.

Allerdings kann nicht ausgeschlossen werden, dass sich Schleiermacher ein neues Heft, einzelne Bogen oder Zettel für die Abfassung der restlichen ca. 9 Vorlesungsstunden zur Behandlung von Malerei und Poesie angelegt hatte. Das als „M“ lesbare Zeichen könnte dann evtl. auch ein Verweis auf ein Ergänzungsheft sein, von dem sich jedoch keine Spuren nachweisen lassen. Odebrecht hat dem Kollegheft 1819 das sog. „Heft B“ angehängt, das er für ein Autograph Schleiermachers zum Kolleg 1825 hielt, welches sich jedoch als eine anonyme Nachschrift des Kollegs 1825 erwiesen hat. Weil von dem Abbruch auch die Marginalien für die Kollegien 1825 und 1832/33 betroffen sind, feblen auch für das Kolleg 1825 Ausführungen zur Malerei und Poesie, die in den bekannten Nachschriften allerdings vorliegen. Für

131 Vgl. Brief von F. Schleiermacher an Joachim Christian Gaß vom 2. Juni 1819, in: Schleiermachers Briefwechsel mit J. Chr. Gaß (Anm. 46), S. 172-175, hier: 174. 
das Kolleg 1832/33 fehlen Ausführungen zu den bildenden und zu den redenden Künsten fast gänzlich, die auch wiederum in den Nachschriften teilweise detailliert dokumentiert sind. In der Nachschrift Schweizer finden sich beispielsweise Besprechungen zur Malerei mit Beispielen von Gemälden der sog. Düsseldorfer Schule, die Schleiermacher offenbar bei der 27. Kunstausstellung der Akademie der Künste 1832 gesehen hat, von denen er auch einige Werktitel und Künstlernamen mitteilt. Ob Schleiermacher diese Ausführungen gänzlich obne Vorlesungsmanuskript vorgetragen hat, ist zwar nicht undenkbar, aber auch nicht sehr wahrscheinlich. Die Notizen I und II konnten dem Kolleg 1832/33 nicht eindeutig zugeordnet werden. Es ist somit nicht auszuschließen, dass einzelne ergänzende Bogen oder Zettel mit Ausführungen über die bildenden und redenden Künste verschollen sind.

Schleiermacher hat dieses Kollegheft wohl im Verlauf der fünfwöchigen Vorbereitungszeit zum Ästhetikkolleg 1819 angelegt und begonnen, d.h. nach und während der Abfassung der Notizen I und II, deren Inhalt dann größtenteils in es einging. Die Hinweise auf eine sukzessive Niederschrift des Heftes während der Durchführung des Kollegs lassen eine Entstehungszeit während der Monate April, Mai, Juni und Juli 1819 wahrscheinlich erscheinen. Da das Heft mit der 64. Stunde abbricht, die auf den 21. Juli datiert werden kann, ist damit auch der wahrscheinliche Zeitpunkt für den Abschluss der Ausführungen des Kollegheftes 1819 angegeben. Die erhaltenen Marginalien zum Kolleg 1825 dürften dann größtenteils während dessen Durchführung im Sommersemester 1825 entstanden sein.

\section{Marginalien zum Kolleg 1832/33}

Manuskript: ABBAW, SN 109. Erstveröffentlichung und Seitenkonkordanz: Edition Odebrecht (ÄOd).

Die Marginalien sind von Schleiermacher an den Rändern des Kollegheftes 1819 in kleiner und enger Schrift und in zusammenhängenden Blöcken - häufig über Seitenwechsel hinweg - mit der üblichen Eisengallustinte notiert worden. Sie dienten der Durchführung des Kollegs 1832/33 und lassen eine konzeptuelle Umgestaltung des Kollegs erkennen: Die historische Einleitung wird ausgeweitet, der allgemeine Teil enthält Bezüge auf das Konzept des „unmittelbaren 
Selbstbewusstseins" und die einzelnen Künste des besonderen Teils werden überarbeitet. Die zunächst mit Stundenzablen versehenen Marginalien brechen noch vor dem Ende des Kolleghefts bei Stunde 59 auf Seite 72 ab, danach tauchen nur noch vereinzelte Marginalien auf, die nachträglich den Stunden 67-68 und 89-90 zugewiesen werden konnten, während das Kolleg über insgesamt 104 Stunden verlief. Dieser Befund könnte die bereits erwogene Annabme eines Überlieferungsverlusts bekräftigen: Schleiermacher hat möglicherweise noch über Notizen für die ca. 41 restlichen Stunden des Kollegs 1832/33 verfügt, die heute nicht mehr erhalten sind.

Odebrecht gibt die Marginalien in seiner Edition als ,Vorlesungsnotizen von 1832/33 " heraus, rechnet die ersten Randnotizen auf der Titelseite des Kollegheftes, die die drei "Avancements der Ästhetik" betreffen, jedoch fälschlich dem Kolleg 1819 bzw. 1825 zu. Schleiermacher hat diese "Avancements", die die grundlegenden Positionen zur Ästhetik von 1. Kant und Schiller, 2. Fichte und Schelling und 3. Hegel refererieren, aber nachweislich erst für das Kolleg 1832/33 entwickelt und darin in der historischen Einleitung abgehandelt. Das geht nicht nur aus einem Textvergleich mit der Nachschrift Schweizer hervor, sondern auch aus dem Sachverhalt, dass Schleiermacher darin Passagen aus Hegels „Enzyklopädie der philosophischen Wissenschaften im Grundrisse" in der zweiten Ausgabe von 1827 teilweise wörtlich zitiert; er besaß zwar auch die Ausgabe von 1817, in der die zitierten Passagen jedoch noch nicht vorkommen. Die auch im Rauchschen Auktionskatalog aufgeführte zweite Ausgabe der „Enzyklopädie" Hegels erwarb Schleiermacher am 26. Januar 1830 über seinen Verleger Reimer. ${ }^{132}$ Er rekurriert hiermit erstmals im Rahmen seiner Ästhetik dezidiert auf Hegels Kunstphilosophie und betrachtet diejenige Schellings als deren Vorstufe; hingegen dürfte Schleiermacher von Hegels Berliner Vorlesungen über die Philosophie der Kunst nur vom Hörensagen oder aus dem Lektionskatalog der Berliner Universität erfahren haben, da Hothos Edition derselben erst 1835-38 erschienen ist.

Bis auf wenige gekennzeichnete Ausnabmen enthalten die Marginalien eine eigene Stundenzählung und Jabresangaben; in Abgleich mit den Tageskalendern 1832 und 1833 sowie mit der Nachschrift Schweizer konnten alle 104 Stunden datiert werden. Ab der

132 KGA I/15, S. 732. 
59. Stunde wird die Stundenzählung nicht mehr kontinuierlich weitergeführt, die einzelnen Notizen auf den Seiten 82 und 90 konnten erst nach Abgleich mit der Nachschrift Schweizer den Stunden 67 und 68 bzw. 89 und 90 zugewiesen werden. Zudem stimmen die Stundenangaben nur bis zum 21. Dezember 1832 mit den Angaben von Schleiermachers Tageskalender 1832 überein. Ab dem 3. Januar 1833 ändert sich dieser Befund: Im Manuskript und im Tageskalender 1833 notiert Schleiermacher „44. Stunde“, obwobl er diese im Tageskalender 1832 bereits für den 21. Dezember als letzte gehaltene Stunde des Jahres notiert hat. Auch in Hinblick auf die Stundenkennzeichnungen der Nachschrift Schweizer muss die erste Stunde des Jahres 1833 die 45. Stunde gewesen sein. Daher ergibt sich, anders als im Tageskalender 1833 notiert, eine Gesamtanzahl von 104 statt 103 Stunden.

Schleiermacher platzierte die Marginalien häufig parallel zu den Kapitelanfängen der Niederschrift von 1819, sie verteilen sich im Manuskript wie folgt (in Klammern mit Seiten- und Zeilenangaben in dieser Edition):

1. Block (Einleitung):

S. 1 (39,4-8)

2. Block:

S. $5(43,14-25)$

3. Block (allg. Teil):

S. $7(45,9-46,4)$

S. $8(46,4-36)$

4. Block:
S. $10(47,30-48,25)$

S. $11(48,25-49,17)$

S. $12(49,17-50,7)$

S. $13(50,8-51,1)$

S. $14(51,1-32)$

S. $15(51,32-52,18)$

S. $16(52,19-53,12)$

5. Block:

6. Block:

7. Block (Mimik):
S. $35(71,9-72,4)$

S. $36(72,4-26)$

S. $40(76,14-77,3)$

S. 41 (77,7-16)

S. 57 (92,2-19)

S. $58(92,19-93,19)$

S. $59(93,19-94,14)$

S. $60(94,14-95,16)$

S. $61(95,16-96,6)$ obne Stundenangabe

Stunde 1 bis 9

Stunde 10 bis 14

Fortsetzung Stunde 14 bis 18

Stunde 19 bis 21

Stunde 22 bis 25

Fortsetzung Stunde 25 bis 28

Fortsetzung Stunde 28 bis 31

Stunde 31 bis 33

Fortsetzung Stunde 33 bis 36

Fortsetzung Stunde 36 bis 37

Stunde 38

Fortsetzung Stunde 38 bis 39

Stunde 40 bis 42

Stunde 43 bis 44

Stunde 45 bis 46

Fortsetzung Stunde 46 bis 47

Fortsetzung Stunde 47 bis 48

Fortsetzung Stunde 48 bis 50

Fortsetzung Stunde 50 bis 52 


$\begin{array}{lll} & \text { S. } 62(96,6-40) & \text { Fortsetzung Stunde } 52 \text { bis } 53 \\ & \text { S. } 63(96,40-98,6) & \text { Stunde } 54 \text { bis } 55 \\ & \text { S. } 64(98,6-99,6) & \text { Fortsetzung Stunde } 55 \text { bis } 56 \\ & \text { S. } 65(99,15-100,3) & \text { Fortsetzung Stunde } 56 \text { bis } 57 \\ \text { 8. Block (Musik): } & \text { S. } 71(105,32-106,13) & \text { Fortsetzung Stunde } 57 \text { bis } 59 \\ & \text { S. } 72(107,2-9) & \text { Fortsetzung Stunde } 59 \\ \text { 9. Block (Architektur): } & \text { S. } 82(118,7-36) & \text { Zwei Notizen (St. } 67 \text { und 68) } \\ \text { 10. Block (Skulptur): } & \text { S. } 90(127,20-128,13) & \text { Fünf Notizen (St. } 89 \text { bis 90) }\end{array}$

Die Marginalien dürften kurz vor und während der Durchführung des Kollegs im Wintersemester 1832/33 entstanden sein und damit zeitlich nach der ersten und der zweiten Rede „Über den Umfang des Begriffs der Kunst" und vor der geplanten dritten.

\section{Zweiter Teil. Vorlesungsnachschriften}

Insgesamt sind 11 Nachschriften zu Schleiermachers Ästhetikvorlesungen bekannt, von denen sieben in unterschiedlichen Überlieferungszuständen erhalten sind, drei von diesen - zu jedem Kolleg einewerden in diesem Band ergänzend zu Schleiermachers Vorlesungsmanuskripten wiedergegeben.

\begin{tabular}{|c|c|c|c|}
\hline Kolleg & Nachschreiber & Manuskript & Überlieferung / Archiv \\
\hline 1819 & Blubme & verschollen & $\begin{array}{l}\text { ÄOd enthält umfangreiche } \\
\text { Auszüge }\end{array}$ \\
\hline 1819 & Wigand & verschollen & ÄLo enthält wenige Auszüge \\
\hline 1825 & Bindemann & erhalten & $\begin{array}{l}\ddot{A} L o \text { (kompiliert) und ÄOd enthal- } \\
\text { ten Auszüge / ABBAW, SN } 581\end{array}$ \\
\hline 1825 & Trendelenburg & erhalten & $\begin{array}{l}\text { unveröffentlicht / Handschriften- } \\
\text { abteilung StaBi Berlin, A } 24\end{array}$ \\
\hline 1825 & Anonymus & Fragment & ÄOd / ABBAW, SN 582 \\
\hline 1825 & Braune & verschollen & $\begin{array}{l}\text { ÄLo (kompiliert) enthält wenige } \\
\text { Auszüge }\end{array}$ \\
\hline $1832 / 33$ & Schweizer & erhalten & $\begin{array}{l}\text { ÄLo (kompiliert) / Handschriften- } \\
\text { abteilung UB Zürich, VIII } 33\end{array}$ \\
\hline $1832 / 33$ & Henke & Fragment & $\begin{array}{l}\text { unveröffentlicht / UB Marburg, } \\
\text { Ms 649, S. 73-92 }\end{array}$ \\
\hline
\end{tabular}




$\begin{array}{llll}\text { 1832/33 Stern } & \text { Fragment } & \begin{array}{l}\text { unveröffentlicht / Handschriftenab- } \\ \text { teilung StaBi Berlin, Nachlass 304, } \\ \text { Mappe } 5\end{array} \\ 1832 / 33 \text { Erbkam } & \begin{array}{l}\text { verschollen } \\ \text { ALLo (kompiliert) } \\ 1832 / 33\end{array} \text { George } & \text { verschollen } & \text { ÄLo (kompiliert) }\end{array}$

\section{Kolleg 1819 (sekundäre Überlieferung)}

Als einzige relativ umfangreiche Vorlesungsnachschrift des Kollegs 1819, das vom 19. April bis zum 7. August 1819 in ca. 73 Stunden verlief, ist die Nachschrift Bluhme durch die Edition Odebrechts überliefert. Odebrecht gibt von der Titelseite nur diese Sequenz wieder: „A[ngefangen] d[en] 19. April 1819, F[riedrich] Bl[ubme]“.. ${ }^{133}$ Friedrich Bluhme (1797-1874) wurde in Hamburg als Sobn eines Kaufmanns geboren, er war an der Berliner Universität vom 10. Oktober 1818 bis zum 14. Oktober 1819 an der Juristischen Fakultät immatrikuliert, hörte in dieser Zeit zwei philosophische Vorlesungen bei Schleiermacher und schloss sein Studium als Dr. jur. und theol. ab. Später wurde er Geheimer Justizrat und ab 1843 Professor für Kirchenrecht an der Universität Bonn. Odebrecht berichtet über das Manuskript, dass es in der Universitätsbibliothek Bonn unter der Signatur „S 839“ aufbewahrt wurde; laut Auskunft einer Bibliothekarin gilt es inzwischen als Kriegsverlust. Odebrecht beschreibt das Manuskript wie folgt: „Es ist ein 311+270 Seiten umfassender Halblederband, der im ersten Teil die Dialektik von 1818/1819, im zweiten Teil die Ästhetik von 1819 enthält. [...] Zusätze oder nachträgliche Ausarbeitungen sind nirgends festzustellen. Die Schrift ist sorgfältig, leserlich und mit vielen leicht und einwandfrei deutbaren Siglen durchsetzt. Beide Teile tragen am Rande später hinzugesetzte Kapitelüberschriften, die von mir größtenteils unter entsprechender Kennzeichnung $(B l)$ verwendet worden sind." 134

Weil Odebrecht ausfübrliche Passagen der Nachschrift in kleinem Schriftgrad in den laufenden Text des Kollegheftes 1819 eingeschoben hat und die Mitteilung von Auszügen mit dem Abbruch des Kollegheftes bis auf einzelne Ausnabmen beendet, ist die Nachschrift nur fragmentarisch überliefert. Für seine Edition musste Odebrecht sowohl

133 Schleiermacher: Ästhetik, hg.v. Odebrecht (Anm. 91), S. 1.

134 Schleiermacher: Ästhetik, hg.v. Odebrecht (Anm. 91), S. XXXI-XXXII. 
die Abhandlung des Kollegheftes als auch den Text der Nachschrift fragmentieren, was den Effekt hat, dass nicht mehr eindeutig nachvollziehbar ist, ob die Auszüge aus der Nachschrift ursprünglich zusammenhingen oder nicht und ob Passagen fehlen oder nicht. Aufgrund dieses Befundes sind in der Wiedergabe dieser Nachschrift an den Stellen, wo in der Edition Odebrechts die Passagen des Kollegheftes 1819 abgedruckt sind, kursivierte eckige Klammern als Zeichen für einen möglichen Textverlust eingesetzt.

Über seine Textbearbeitung der Nachschriften Blubme und Bindemann äußert Odebrecht: „So sind denn hier und dort einige Satzanfänge geändert worden. Auch waren Umstellungen von kleineren Satzgruppen erforderlich, die durch die Gedankenbewegung in den Grundheften bedingt waren. Streichungen nabm ich überall dort vor, wo Nachschrift und Grundheft inhaltlich völlig übereinstimmen. Offenbare Flüchtigkeiten und allzu ungeschickte Formulierungen des Nachschreibers wurden beseitigt [...]. Die Orthographie dieser Texte habe ich modernisiert; denn es wollte mir nicht zusagen, die vielen Abkürzungen und Siglen der Nachschriften nach altertümelnder Orthographie zu ergänzen. "135 Der ursprüngliche Text muss demnach über eine dem früheren 19. Jahrhundert entsprechende Orthographie verfügt haben und auch syntaktisch etwas anders strukturiert gewesen sein als in der Ausgabe von Odebrecht. In den Fällen, wo dieser nur Satzteile oder einzelne Sätze aus der Nachschrift Bluhme wiedergibt, werden für das Verständnis nötige Passagen aus Schleiermachers Kollegheft ergänzt.

Obwohl die Nachschrift trotz dieser Kompilationstechnik relativ ausfübrlich wiedergegeben ist (zu jeder enthaltenen Vorlesungsstunde zumindest einige Passagen), reicht der besondere Teil über die einzelnen Künste nur bis zur Behandlung der Skulptur. Mit dem Abbruch des Kollegheftes 1819 bringt Odebrecht ab Seite 205 das sog. „Heft B“ als Ergänzungsheft, das sich jedoch als die Nachschrift Anonymus 1825 erwiesen hat. Aufgrund der relativen Ausführlichkeit dieser Nachschrift und des gewechselten Jahrgangs folgen ab der Skulptur nur noch vereinzelte Auszüge aus der Nachschrift Blubme und stattdessen mehrere Passagen aus der Nachschrift Bindemann 1825. Die kontinuierlichen Seitenangaben, die Odebrecht durchgehend mit dem Kürzel „Bl.“ versieht, und ebenfalls von einer relativ ausführlichen

135 Schleiermacher: Ästhetik, hg.v. Odebrecht (Anm. 91), S. XXXIV. 
Wiedergabe des Heftes zeugen, brechen mit Manuskriptseite 242 (von ursprünglich 270) ab; in dieser Ausgabe werden diese Seitenangaben mit runden Klammern an den Stellen mitgeteilt, wo auch Odebrecht sie anbringt. Die letzten sporadischen Auszüge der Nachschrift sind von Odebrecht umgestellt worden: Nach einem Auszug von Manuskriptseite 244 folgen welche von den Seiten 250, 247-249 und 247. Durch die Umstellung in die richtige Reihenfolge mussten die Seitenzablen der Referenzquelle entsprechend angepasst werden. Odebrecht gibt auch einige von Blubme notierte Termine wieder, die zur Datierung der Vorlesungsstunden auch des Kollegheftes 1819 herangezogen werden konnten. ${ }^{136}$ Relevante textkritische Anmerkungen Odebrechts werden im Textapparat, die aus der Nachschrift Blubme ergänzten Überschriften im Haupttext wiedergegeben - diese bieten einen anderweitig nicht überlieferten Inhaltsüberblick des Kollegs 1819, der auch für die Kollegien 1825 und 1832/33 relevant ist. Fehlende Überschriften wurden ergänzt.

Die Nachschrift Wigand gilt als verschollen, sie stammt von Eugen Anton Wigand (1795-1843). ${ }^{137}$ Die einzigen von Lommatzsch mitgeteilten Sätze aus dieser Nachschrift über die Poesie werden am Ende der Nachschrift Blubme mit entsprechender Quellenangabe wiedergegeben. Weil sonst keine Nachschriften zum Kolleg 1819 überliefert sind, konnte kein eingehender Textvergleich durchgeführt werden - die Qualität der Nachschrift Bluhme musste daher durch einen inhaltlichen Vergleich mit Schleiermachers Kollegheft 1819 eingeschätzt werden, mit dem sie allerdings durchgehend eindeutige Korrelationen aufweist.

\section{Kolleg 1825}

Die Nachschrift Bindemann gibt Schleiermachers Ästhetikkolleg 1825, das er vom 11. April bis zum 9. September 1825 über 88 Stunden hielt, vollständig wieder. Das Manuskript (ABBAW, SN 581) wird hier erstmals vollständig veröffentlicht, Auszüge enthalten die Editio-

\footnotetext{
136 Vgl. oben „Historische Einführung“, „Zum Kolleg 1819“.

$137 \mathrm{Zu}$ den Kurzbiographien der hier nur erwähnten Nachschreiber siehe: Holden Kelm: „Zu den Hörern von Friedrich Schleiermachers Vorlesungen und ihren Nachschriften“, in: Zeitschrift für Neuere Theologiegeschichte, hg.v. Mark D. Chapman, Theodore M. Vial, Jr. und Friedrich Wilhelm Graf, Bd. 25, Heft 1-2, Berlin 2018, S. 156-234.
} 
nen Lommatzsch (kompiliert) und Odebrecht. Auf dem Titelblatt notierte Bindemann: „Aesthetik. - von Dr. Schleiermacher. - Berlin, Sommersemester 1825. M. Bindemann “. Ernst Moritz Heinrich Bindemann (1803-1858) wurde als Sohn eines Predigers in Schwedt (Oder) geboren, besuchte ein Gymnasium in Stettin und war vom 28. April 1824 bis zum 24. Februar 1827 an der theologischen Fakultät der Berliner Universität immatrikuliert. Schleiermacher bezengte ihm im Abgangszeugnis „fleißigen Besuch" seiner Vorlesungen. Später wurde Bindemann Rektor und Prediger in Pasewalk und ab 1837 Pastor in Beyersdorf.

Lommatzsch kompiliert ergänzend zur Abhandlung der Poesie einige Passagen aus der Nachschrift Bindemann mit derjenigen von Braune. ${ }^{138}$ Odebrecht hingegen nutzt die Nachschrift Bindemann ergänzend zur Wiedergabe des besonderen Teils des Kollegs 1825, vor allem aber zum Ersatz der in der Nachschrift Anonymus 1825 fehlenden Ausführungen über den Roman. ${ }^{139}$

Das Manuskript besteht aus einem fest gebundenen Folioband mit 144 größtenteils beidseitig beschriebenen Blättern, es endet auf Seite 287; die Seiten 47 und 48 sind unbeschrieben und bilden das Ende des dritten Bogens. Die insgesamt 18 Bogen wurden wohl noch von Bindemann selbst durchgehend nummeriert, die Nummern der recto-Seiten hingegen nachträglich wohl von Archivseite mit Bleistift ergänzt. Der durchgehend mit Tinte geschriebene Text ist mit vielen Kürzeln und Kontraktionen versehen und verzichtet weitgehend auf Interpunktionen und Absätze. Die Kapitelüberschriften sind nicht vollständig und wurden daher anhand der überlieferten Inhaltsangaben des Kolleghefts und der parallel überlieferten Nachschriften ergänzt. Das Schriftbild ist ungleichmäßig und ändert sich offenbar in Abhängigkeit davon, ob es sich um Passagen einer direkten Mitschrift oder um Passagen einer nachträglichen Bearbeitung des Mitgeschriebenen handelt. Einige Wechsel von hellerer und dunklerer Tinte deuten wohl Stundenwechsel an, die nicht speziell markiert sind; da diese Wechsel nicht regelmäßig erkennbar sind, erlauben sie keine Ergänzung der Stundennummern; einzelne Stunden wurden aufgrund der Einträge aus Schleiermachers Tageskalender 1825 mit Datumsangaben versehen.

138 Schleiermacher: Ästhetik, hg.v. Lommatzsch (Anm. 86), S. 691-710.

139 Schleiermacher: Ästhetik, hg.v. Odebrecht (Anm. 91), S. XXXV. 
Bis einschließlich Bogen 14 scheint es sich überwiegend um direkte Mitschriften zu handeln, von Bogen 15 bis 18 hingegen überwiegend um nachträgliche Bearbeitungen des Mitgeschriebenen. Dabei hat sich der Bogen 13 (S. 193-208) als redundant erwiesen: Er gibt nahezu denselben Inhalt wieder wie Bogen 15 (S. 225-233), der inhaltlich jedoch weiterführend ist und an den Bogen 16 lückenlos anschließt. Offenbar schrieb Bindemann seine Mitschriften vom Bogen 13 auf dem Bogen 15 ins Reine, vergaß dann aber Bogen 13 zu entsorgen und heftete ibn nach Bogen 12 ein, so dass das Manuskript jetzt zwei textgenetisch verschiedene Fassungen der selben Vorlesungsstunden enthält. In dieser Ausgabe wird mit dem Bogen 15 die letztgültige Textgestalt wiedergegeben, während der Bogen 13 nur auszugsweise, sofern er verständnisfördernde Varianten und Zusätze enthält, in den Sachapparat des Bogens 15 aufgenommen wurde. Daher folgt im edierten Text nach dem Bogen 12 (S. 177-192) direkt der Bogen 14 (S. 209-224).

Die Nachschrift Bindemann ist das bislang vollständigste und ausführlichste Textzengnis des Kollegs 1825. Obwohl die mitunter ausufernden Satzkonstruktionen die Lesbarkeit erschweren, enthalten sie viele begriffliche Differenzierungen, die in den parallel überlieferten Nachschriften nicht mitgeteilt werden, weshalb sie als Leittext dieses Kollegs ediert wurde. Die in den Bogen 15-18 vorkommenden Nachbearbeitungen konnten durch Varianten und Zusätze aus der Nachschrift Trendelenburg ergänzt werden.

Die während des Editionsprozesses aufgefundene und bisher unveröffentlichte Nachschrift Trendelenburg ist in der Handschriftenabteilung der Staatsbibliothek zu Berlin im Nachlass Trendelenburg unter der Signatur A24 archiviert und stammt von Friedrich Adolf Trendelenburg (1802-1872). Die erste Seite ist beschrieben mit „Aesthetik. Bei dem Herrn Professor Schleiermacher in Berlin 1825“. Der mit Tinte beschriebene Folioband enthält 355 beschriebene Seiten, die weder paginiert noch foliiert sind, das Manuskript endet mit der letzten Kollegstunde, worauf der Datumsvermerk hinweist: „Berlin. September 9. 1825“. Der Text des Heftes trägt den Charakter einer direkten Mitschrift und bricht an einigen Stellen ohne erkennbaren Grund ab, einige Seiten sind unbeschrieben. Nach Abgleich mit der Nachschrift Bindemann fehlen dem Manuskript im Verlauf mehrere Vorlesungsstunden, die Trendelenburg möglicherweise nicht besucht hat; laut Abgangszengnis war er im Sommersemster 1825 auch 
für zwei Kollegien von August Neander, zwei von Carl Ritter und für ein Kolleg von August Boeckh eingeschrieben. Ein offenbar versehentlich in die Abhandlung der Mimik eingebundener Bogen, der die Seiten 147 bis 167 umfasst, gehört ursprünglich in den allgemeinen spekulativen Teil ab Seite 102 und müsste dann bis Seite 122 verlaufen.

Die Nachschrift ist trotz ibres größeren Seitenumfangs weniger ausführlich als die Nachschrift Bindemann. Die Lesbarkeit wird durch relativ wenige und leicht erschließbare Kürzel, bündige und verständige Satzbildungen gewährleistet, die aber im Vergleich zur Nachschrift Bindemann an einigen Stellen begriffliche Differenzierungen vermissen lassen; einige Kapitelüberschriften fehlen.

Die Nachschrift Anonymus ist fragmentarisch überliefert, sie wird im Schleiermacher-Nachlass des Archivs der BBAW aufbewahrt unter der Signatur SN 582. Auf dem erhaltenen Deckblatt findet sich der Titel: "Aesthetik von Schleiermacher" obne Jahresangabe - ein Parallelstellenvergleich mit den Nachschriften Bindemann und Trendelenburg deutet mit hoher Wabrscheinlichkeit auf das Kolleg 1825. Die gut lesbare Schrift weist relativ wenige Abkürzungen und Kontraktionen auf, Spuren einer Stundenzählung sind nicht vorhanden, einige Streichungen und Randnotizen lassen vermuten, dass das Heft mindestens einmal nachbearbeitet wurde, womit es sich vermutlich um keine direkte Mitschrift handelt. Bei dem gebundenen Heft im Quartformat ist eine Bogenzählung von 9-19 erkennbar, es enthält 36 beidseitig mit Tinte beschriebene Blätter, wobei die recto-Seiten nachträglich am unteren Seitenrand mit Bleistift nummeriert wurden. Einige Bogen des Bandes sind verschollen, was offenbar vor seiner Deponierung im „Litteraturachiv-Berlin“, von dem ein roter Stempel auf Seite 1 zu erkennen ist, geschehen ist. Der vordere Teil (8 Bogen) und damit vermutlich auch die Namensangabe des Nachschreibers wurde herausgerissen, von Bogen 16 fehlen wohl 2 Blätter, Bogen 17 gänzlich und auch am Ende ist mindestens eine Seite grob entwendet worden (ein nicht ganz abgerissenes Seitenstück heftet noch an). Das Fragment setzt mit der Diskussion der Verzierungen in der Architektur ein und endet in dem Kapitel über die redenden Künste, das aufgrund des fragmentarischen Zustands unvollständig ist.

Odebrecht nabm aufgrund des relativ gleichmäßigen Schriftbildes und der grafischen Merkmale der Handschrift an, dass es sich um ein Manuskript Schleiermachers zum Kolleg 1825 handele, das dieser für eine mögliche Veröffentlichung ins Reine geschrieben habe. ${ }^{140}$

140 Schleiermacher: Ästhetik, hg.v. Odebrecht (Anm. 91), S. XXVIII-XXX. 
Diese Annabme lässt sich schon durch einen Vergleich mit Schleiermachers Handschrift im Kollegheft 1819 und unter Berücksichtigung seiner gewöhnlichen Orthographie und Interpunktion ausschließen. Auch die von Lehnerer bekräftigte Hypothese Odebrechts, die für Schleiermacher untypische Handschrift könnte durch eine persönliche Lebenskrise hervorgerufen worden sein, erscheint angesichts des Schriftbildes als unnötig; für eine solche Krise gibt es auch keine hinreichenden Belege. ${ }^{141}$ Die abweichenden Merkmale in Handschrift, Orthographie und Interpunktion, die Anlage des Heftes und der charakteristische Textfluss hätten beide Herausgeber dazu bringen können, darin eine Vorlesungsnachschrift zu erkennen. Odebrecht gibt die ihm bereits als Fragment vorliegende Nachschrift bis auf einige Lesefehler und Umstellungen vollständig wieder, er ergänzt sie nur am Ende um einige Ausführungen über den Roman aus der Nachschrift Bindemann. Der Textbestand des anonymen Nachschriftfragments geht nicht über den der Nachschriften Bindemann und Trendelenburg hinaus, weshalb sie in dieser Ausgabe nicht berücksichtigt wurde.

Die Nachschrift Braune lag Lommatzsch noch vor und gilt inzwischen als verschollen; sie stammt von Heinrich Wilhelm Julius Braune (1805-1871). Lommatzsch gibt einige Passagen daraus ergänzend zum Kapitel über die Poesie wieder, kompiliert diese aber offenbar mit entsprechenden Passagen der Nachschrift Bindemann. Aufgrund der relativ guten Überlieferungslage und der Feststellung einer nicht über den bekannten Textbestand hinausgehenden Überlieferung der Passagen durch Lommatzsch, wurde die Nachschrift Braune in dieser Ausgabe nicht weiter berücksichtigt.

\section{Kolleg 1832/33}

Das Manuskript der Nachschrift Schweizer befindet sich im Nachlass Schweizer, in der Handschriftenabteilung der Zentralbibliothek Zürich (VIII-33). Die Nachschrift wurde erst in jüngerer Zeit wieder aufgefunden und dokumentiert Schleiermachers letztes Ästhetikkolleg, das vom 23. Oktober 1832 bis zum 29. März 1833 über 104 Stunden verlief; sie trägt auf dem Titelblatt die Überschrift: „Schleiermachers Vorlesungen über die Aesthetik nachgeschrieben und mit Inhaltsverzeichnis am Rande versehen von Alexander Schweizer, Zü-

141 Schleiermacher: Ästhetik, hg.v. Lehnerer (Anm. 97), S. XIX. Vgl. Anm. 96. 
rich". Alexander Schweizer (1808-1888) wurde in der Schweiz, in Murten (Kanton Freiburg), als Sohn eines Geistlichen geboren. Er ging 1818 auf das Gymnasium in Biel und wechselte 1821 nach Basel, ab 1822/23 besuchte er die Zürcher Gelehrtenschule und bis 1825 das Collegium Humanitatis. Anschließend studierte er am Collegium Carolinum, der Vorgängerinstitution der 1833 gegründeten Universität Zürich, Philologie, Philosophie und Theologie, und erhielt seine Ordination 1831. Wie für Absolventen seines Standes üblich, legte Schweizer 1832 nach seinem Examen ein Studienjahr an einem Ort seiner Wabl ein und immatrikulierte sich vom 21. April 1832 bis zum 31. März 1833 an der Berliner Universität, wo er überwiegend Schleiermacher hörte. Seine intensiven Schleiermacherstudien und die geknüpften Kontakte mit Schleiermacherschülern dürften dazu beigetragen haben, dass Schweizer als Herausgeber von Schleiermachers Vorlesungen über die philosophische Ethik im Rahmen der „Sämmtlichen Werke" (SW 3,5) tätig wurde. 1834 wurde Schweizer Privatdozent an der Zürcher Universität, 1840 Professor für Praktische Theologie und 1844-71 war er Pfarrer des Großmünsters in der Altstadt von Zürich.

Für Schleiermachers letztes Ästhetik-Kolleg ist diese Nachschrift das bislang vollständigste und ausführlichste Zeugnis und wurde daher als Leittext ediert. Das Manuskript ist in einem Folioband gebunden und enthält laut der Zählung am oberen Seitenrand 29 Bogen und 237 von Schweizer selbst paginierte Seiten, die mit dunkelbrauner Tinte beschrieben sind. Hierbei handelt es sich offenbar um einen während der Vorlesung verfassten Text, was an den zablreichen Abkürzungen und einigen offensichtlich in Eile verfassten Schriftzügen deutlich wird. Bei einer Durchsicht wurden die Seitenränder von Schweizer nachträglich mit ausführlichen Inhaltsangaben beschrieben, die hier nicht berücksichtigt wurden. Meist an den inneren Seitenrändern hat Schweizer mit einem kurzen waagerechten Strich die Stundenwechsel notiert, von denen ausgehend alle 104 Stunden gekennzeichnet und datiert werden konnten. Die Gliederung des Vorlesungstextes ist nicht kohärent: Schweizer hält sich nicht immer an die anfangs eingeführte Kapitelzählung und lässt einzelne Kapitelüberschriften aus bzw. nennt sie nur am Rand. Die wiedergegebene Gliederung folgt weitgehend der von Schweizer selbst vorgenommenen, korrigiert diese aber an fehlerhaften Stellen in Anlehnung an Schleiermachers Kollegheft 1819 und den anderen Nachschriften. 
Lommatzsch lag die Nachschrift Schweizer als eine von drei Nachschriften des Kollegs 1832/33 vor und hat sie offenbar als Leittext seiner Edition herangezogen. Wenngleich einige Stellen anders formuliert sind und einige Passagen der Edition von 1842 in der Nachschrift Schweizer nicht vorhanden sind, ist der inhaltliche Aufbau, die Abfolge der Kapitel und Absätze, teilweise bis hin zum Wortlaut der einzelnen Sätze identisch. Daher konnte eine Seitenkonkordanz mit der Edition Lommatzsch erstellt werden, die kursiv am Seitenrand mitgeteilt wird.

Die Nachschrift Stern ist in der Handschriftenabteilung der Staatsbibliothek zu Berlin im Nachlass Stern in der Mappe 5 archiviert und setzt direkt mit der 28. Stunde vom 29. November 1832 ein, also gut fünf Wochen nach dem offiziellen Beginn der Vorlesung; sie ist aus der Hand von Sigismund Stern (1812-1867). Die feblende Überlieferung eines Titelblattes lässt vermuten, dass das lose gebundene Heft nur fragmentarisch erhalten ist. Auch nach der 28. Stunde ist die Nachschrift im Vergleich zu den Parallelüberlieferungen undetailliert und wenig materialreich; die einzelnen Künste sind nur sehr knapp oder lückenhaft dokumentiert. Am Rand hat Stern einige Termine notiert, die auf eine unregelmäßige Teilnahme der Vorlesung deuten, womit auch der überlieferte Teil der Nachschrift als unvollständig gelten muss. Laut dem überlieferten Abschlusszeugnis bezeugte Schleiermacher Stern einen „rühmlich fleißig[en]" Besuch seiner letzten Ästhetikvorlesung. Neben Schleiermacher hörte Stern im Wintersemester 1832/33 auch zwei Vorlesungen von August Boeckh und je eine von Henrich Steffens, Friedrich Eduard Beneke und Franz Bopp.

Die Nachschrift Henke ist eine fragmentarische Überlieferung des Kollegs 1832/33, die an der Universitätsbibliothek Marburg mit der Signatur Ms 649 archiviert wird. Die Nachschrift stammt von Ernst Ludwig Theodor Henke (1804-1872) und ist auf den Blättern 73-92 eines Heftes niedergeschrieben, das im vorderen Teil eine vollständige Nachschrift von Schleiermachers Kolleg über Hermeneutik von 1832/33 enthält. Die Nachschrift enthält nur den letzten Abschnitt über die Poesie, der Titel lautet dementsprechend: „Schleiermacher über die Poesie. (Schluss seiner Vorlesungen über Aesthetik, Berlin, im März 1833.) “Dieser Abschnitt über die Poesie ist ausführlich, jedoch im Textbestand nicht über die Nachschrift Schweizer hinausgehend, weshalb er für diese Ausgabe unberücksichtigt blieb. 
Die Nachschriften Erbkam und George lagen Lommatzsch für seine Edition noch vor und gelten heute als verschollen. Lommatzsch hat sie mit der Nachschrift Schweizer kompiliert, so dass nicht mehr ersichtlich ist, welche Passagen aus welcher Nachschrift stammen.

\section{Anhang}

\section{Musik}

Unveröffentlichtes Manuskript: ABBAW: SN 112/3.

Das Manuskript trägt auf der Titelseite mittig die Überschrift „Musik"; es wurde in der Studienausgabe von Lehnerer als ein Text beschrieben, in dem Schleiermacher "Detailfragen der Musiktheorie" notiert. Es besteht aus 4 halben Bogen, d.h. 8 Blättern im Quartformat und einem Einzelblatt, die zu einem losen Heft gefaltet sind. Bogen 1 bildet den Heftumschlag (Seiten 1-2, 17-18), in Bogen 2 (Seiten 3-4, 7-8) ist nur ein Blatt (Seiten 5-6) eingelegt, das abgerissen wurde, ein zur Risskante passendes Blatt liegt nicht vor; Bogen 3 (Seiten 9-10, 15-16) liegt unter Bogen 2 und enthält den Bogen 4 (Seiten 11-12, 13-14). Alle Bogen bestehen aus derselben Papiersorte und sind offenbar in der ursprünglichen Heftung erhalten. Die 18 Seiten wurden nachträglich mit Bleistift paginiert. Das relativ grobkörnige Papier ist nur auf dem Titelblatt und den Seiten 3 und 5 beschrieben (Eisengallustinte), diese Seiten weisen den für Schleiermacher typischen Rand auf; die restlichen Seiten sind leer.

Die Notizen befassen sich speziell mit der Harmonielehre, der Tonskala und den Intervallen. Die für Schleiermachers Vorlesungsnotizen typischen Erledigungsvermerke und Querverweise fehlen hier, auch gibt es keine Hinweise darauf, dass das Heft mit den Notizen zur Ästhetik I und II ursprünglich in Verbindung stand, schließlich konnten in den Manuskripten und Nachschriften zu den drei Kollegien auch keine inhaltlichen Bezüge zu diesen Notizen festgestellt werden. Aus diesen Gründen kann dieses Heft nicht eindeutig den Ästhetikvorlesungen, sondern vielmehr nur Schleiermachers persönlicher Beschäftigung mit der Musik zugerechnet werden. Dafür spricht auch, dass er laut archivalischem Befund für keine andere Kunstform ein vergleichbares Heft angelegt hat; es war offenbar nur für seine Gedan- 
ken über die Musik bestimmt und mit 18 Seiten deutlich umfangreicher bestückt als für die Notizen am Ende nötig war.

Schleiermachers praktische Beschäftigung mit der Musik geht mindestens zurück auf seinen Eintritt in den Chor der Berliner Singakademie im Jahr 1808 und die sich in den folgenden Jahren anschließenden, teilweise mehrmals wöchentlich dort wahrgenommenen $\mathrm{Mu}$ sikstunden, zu deren Anlass er diese Notizen verfasst haben könnte. Es kann jedoch nicht ausgeschlossen werden, dass er das Heft erst im Zuge seiner ersten Planungen eines Ästhetikkollegs angelegt hat, was laut den erhaltenen Briefzeugnissen spätestens zum Jahresende 1816 der Fall gewesen war. Dieser Plan könnte ibn dazu veranlasst haben, Exzerpte aus einem musiktheoretischen Handbuch zu verfassen, um sich Grundzüge der Musiktheorie anzueignen und diese zu vertiefen, auf die er dann aber in seinen Ästhetikkollegien nicht mehr dezidiert, sondern nur wie auf einmal erworbene Grundkenntnisse zurückgegriffen hätte. Ein solches musiktheoretisches Handbuch konnte in Schleiermachers Bibliothek jedoch nicht nachgewiesen werden.

\section{Notiz zu einem Tranerlied}

Unveröffentlichtes Manuskript. ABBAW, SN 112/4.

Es handelt sich um einen halben, bräunlich gefärbten Papierbogen im Quartformat, der in der Mitte gefaltet wurde; von den vier mit Bleistift nachträglich paginierten Seiten ist nur die Titelseite mit Eisengallustinte beschrieben. Wie der Quellennachweis am Ende des kurzen Textes verdeutlicht, beinhaltet er das Grab-und Trauerlied "Wie sie so sanft rubn", das von Friedrich Burchard Beneken komponiert wurde. Da das Lied in seinen Ästhetikkollegien an keiner Stelle erwähnt wird, handelt es sich hier vermutlich um ein Schriftstück, das Schleiermacher zu einem anderen Anlass verfasst hat.

Einen Hinweis auf eine mögliche Datierung liefert die „Chronik des neunzehnten Jahrhunderts" (1821), in der berichtet wird, dass Schleiermacher für den am 25. Februar 1821 verstorbenen Berliner Propst Gottfried August Ludwig Hanstein eine Grabrede gehalten hat, in deren Folge "Zelters Sing-Akademie“ den ",herrlichen vierstimmigen Gesang des schönen Liedes: Wie sie so sanft ruhen" anstimmte. ${ }^{142}$ Schleiermacher hat diese Notiz somit möglicherweise im

142 Chronik des neunzehnten Jahrhunderts. 1821, hg.v. Carl Venturini, Altona 1824, S. 195 . 
zeitlichen Umfeld dieser Grabrede niedergeschrieben, bei der er das Lied gehört haben dürfte. Es könnte aber auch sein, dass er das Lied als Repertoirestück des Chores der Singakademie kannte, in dem er bereits zwischen 1808 und 1810 häufig mitwirkte, und diese Notizen dementsprechend früher verfasst worden sind.

\section{Notiz zur Ästhetik von Bouterwek}

Manuskript. ABBAW, SN 112/2, 3a. Erstveröffentlichung und Seitenkonkordanz: Edition Odebrecht (ÄOd).

Bereits Odebrecht hatte diesen Zettel mit dem Titel „Aesthetik von Bouterwek" im Heft der Notizen II vorgefunden, in das er aber offenbar erst nachträglich eingelegt wurde. Der Zettel ist aus bräunlichem Papier und wurde aus einer gedruckten akademischen Abhandlung (anscheinend über agronomische Fragen) ausgeschnitten, von der sich auf der Rückseite noch Fragmente finden.

Schleiermacher hat sich hier offenbar Notizen zur zweiten Auflage der "Ästhetik“ Bouterweks ${ }^{143}$ von 1815 gemacht und erörtert einige ästhetische Kategorien. Laut seinem Tageskalender 1825 bestellte er sich diese Ausgabe am 9. April 1825 bei seinem Verleger Reimer. ${ }^{144}$ Da dieser Zettel keine inhaltlichen Entsprechungen zu den Notizen I und II oder zur Abhandlung des Kollegheftes aufweist und sich auch in den Nachschriften der drei Kollegien keine direkten Bezüge zu Bouterweks Ästhetik finden, kann dieser Zettel, obwohl er in zeitlicher Nähe zum Kolleg 1825 entstanden sein könnte, nicht eindeutig den Ästhetikvorlesungen zugewiesen werden. Für diese Annabme spricht auch, dass es an einer Textstelle heißt: „Kann das komische getheilt werden, wie Rec[ensent] thut in das Aesthetisch Lächerliche und das ästhetisch scherzhafte"; denn die Wendung „wie Recensent thut" deutet darauf hin, dass es sich hierbei entweder um die Skizze einer geplanten Rezension Schleiermachers von Bouterweks Ästhetik, oder aber um ein kommentiertes Exzerpt von einer Rezension aus anderer Hand handeln könnte. Zwar plante Schleiermacher gelegentlich Rezensionen, die er dann letztlich nicht ausführte, aber

143 Friedrich Ludewig Bouterwek: Ästhetik, Göttingen 1815.

144 Schleiermacher: Tageskalender 1825, erarbeitet von Elisabeth Blumrich, in: schleiermacher digital / Tageskalender 1808-1834 (Anm. 3). URL: https://schleiermacherdigital.de/tageskalender/index.xql (abgerufen 23.06.2020). 
weil in seiner Ästhetik das Komische nicht dezidiert in das Lächerliche und Scherzhafte eingeteilt wird, ist diese Option doch sehr fraglich. Eine Rezension von Bouterweks Ästhetik von einem Rezensenten, der die genannte Einteilung des Komischen (in seiner Ästhetik) trifft, konnte jedoch im fraglichen Zeitraum nicht nachgewiesen werden, weshalb über den näheren Anlass dieses Zettels einige Fragen offen bleiben.

4. Notizen zur dritten Akademieabhandlung "Über den Umfang des Begriffs der Kunst"

Unveröffentlichtes Manuskript: ABBAW, SN 110, S. 13-18.

Odebrecht sind diese Notizen erst nach seiner Edition aufgefallen, er erwähnt sie in seiner Monographie „Schleiermachers System der Ästhetik" (1932) einleitend, zitiert sie auszugsweise und insistiert auf ibrer Bedeutung, Schleiermachers letzte Worte über die Ästhetik zu enthalten. ${ }^{145}$ Das Manuskript besteht aus einem einseitig beschriebenen Zettel und einem halben Bogen, der in der Mitte gefaltet wurde, so dass vier Seiten entstehen, die durchgängig beschrieben sind. Die Notizen wurden nachträglich an die "Notizen zur Ästhetik I“ angefügt, müssen aber aufgrund ibres Inhalts und Erstellungszeitraums als ein eigenständiges Dokument betrachtet werden. ${ }^{146}$ Es handelt sich dabei um Vorarbeiten Schleiermachers für seine unvollendete dritte Akademieabhandlung „Über den Umfang des Begriffs der Kunst in Bezug auf die Theorie derselben", die er im Gegensatz zu den ersten beiden Abhandlungen nicht mehr vorgetragen hat, offenbar weil sich sein Gesundheitszustand bereits zu Beginn des Jahres 1834 zunehmend verschlechterte. Die Notizen enthalten typische Bearbeitungsmerkmale, die davon zeugen, dass Schleiermacher sie tatsächlich für die Niederschrift der dritten Akademieabhandlung verwendet hat.

Der Zettel beginnt mit der Notiz „Revision des bisherigen“; es folgen Rekurrenzen auf die erste und zweite Akademieabhandlung, die jedoch selbst nicht in den Notizen vorbereitet oder abgehandelt werden. Schließlich zieht Schleiermacher aus der bisherigen Erörterung Schlïsse und formuliert Fragen, die die systematische Anlage der

145 Odebrecht: Schleiermachers System der Ästhetik (Anm. 111), S. 27, 88, 134, 160, $161,184$.

146 Vgl. oben „editorischer Bericht“ zu den „Notizen zur Ästhetik I“. 
Ästhetik betreffen und teilweise in der dritten Abhandlung selbst nicht mehr vorkommen. Darunter befindet sich etwa die folgende Passage, deren Edition durch Ludwig Jonas der Forschung Rätsel aufgab:

„Es ist aber natürlich, da niemand die Mimik der Poesie gleichstellen wird als welche der Gipfel aller Kunst ist, daß diese nicht ganz ans Licht komen konte wo von jener ausgegangen war, und wir werden nicht besser thun als nun das Verfahren umzukehren und von den Künsten welche es mit Gestaltbildung und Rede zu thun haben ausgehen, und wenn wir dann die Ergebnisse beider Wege in einander bauen wird sich das ganze vollenden." 147

Ludwig Jonas gibt diese Passage in seiner Ausgabe der Akademiereden ergänzend zur dritten Abhandlung wieder und bezeichnet sie als eine „dem Manuscript anliegende Bemerkung “, was darauf hindeutet, dass ihm die vorbereitenden Notizen zusammen mit den drei Abhandlungen vorlagen (Präparationen zu den ersten beiden Abhandlungen sind jedoch nicht bekannt). ${ }^{148}$ In späteren Publikationen wurde die von Jonas zitierte Notiz als verschollen betrachtet, vermutlich aus dem einfachen Grund, weil sie dem Manuskript der dritten Abhandlung nicht (mehr) beilag; auch die Datierung dieser Notiz blieb unbestimmt. ${ }^{149}$ Weil sämtliche vorbereitende Notizen für die dritte Akademieabhandlung auf der Rückseite eines Briefes beginnen, der am „9.11.33" mit „Schleiermacher" unterschrieben ist, müssen jedoch nicht nur die Vorarbeiten, sondern auch die dritte Abhandlung selbst nach diesem Datum entstanden sein und somit auch nach dem Ende des Ästhetikkollegs 1832/33.

$$
* * *
$$

Die vorliegende Ausgabe von Schleiermachers Ästhetik ist in den Jahren 2016 bis 2020 an der Schleiermacher-Forschungsstelle der BerlinBrandenburgischen Akademie der Wissenschaften entstanden. Sie basiert auf umfangreichen Vorarbeiten von Dr. Wolfgang Virmond, der im Januar 2020 verstorben ist und in dessen Gedenken diese Ausgabe steht. Die erste Erschließung des überlieferten Materials in den 1990er Jahren, die sukzessive Herstellung der Rohtranskriptionen von Schlei-

147 Notizen zur dritten Akademieabhandlung „Über den Umfang des Begriffs der Kunst", S. 921.

148 SW III,3, S. 224.

149 Als verschollen wird die Passage betrachtet in: Schleiermacher: Ästhetik, hg.v. Lehnerer (Anm. 97), S. 188, der die drei Akademieabhandlungen über den Begriff der Kunst zudem fälschlich in die Jahre 1831/32 datiert, sowie in: KGA I/11, S. 793. 
ermachers Manuskripten (bis auf zwei Notizzettel) und der Nachschriften Bindemann, Anonymus und Henke gehen auf Virmonds akribische Editionsarbeit zurück; ihm gebührt daher der erste große Dank für das Zustandekommen dieser Ausgabe. Das Projekt zu dieser historisch-kritischen Ausgabe wurde dann von Prof. Dr. Andreas Arndt, dem Projektleiter des Akademienvorhabens "Schleiermacher in Berlin 1808-1834. Briefwechsel, Tageskalender, Vorlesungen" initiiert. Daraufhin konnte in den Jabren 2015/16 die Rohtranskription der Nachschrift Schweizer im Rabmen eines Forschungsstipendiums der Gerda-Henkel-Stiftung erstellt werden. Das Editionsprojekt, das neben der Druckausgabe auch aus einer digitalen Edition ${ }^{150}$ besteht, wurde ab 2016 von der DFG im Rabmen einer Eigenen Stelle finanziert und als Drittmittelprojekt mit dem Akademienvorhaben „Schleiermacher in Berlin 1808-1834" der BBAW assoziiert. Prof. Dr. Andreas Arndt, der Arbeitsstellenleiterin Dr. Sarah Schmidt, PD Dr. Simon Gerber und Elisabeth Blumrich möchte ich besonders herzlich für die stetige und freundliche Unterstützung sowie die vielen wertvollen Hinweise danken - obne die tiefgehenden Schleiermacherkenntnisse, die langjährigen Transkriptionserfahrungen und das umfassende Editionswissen der Berliner Schleiermacher-Forschungsstelle wäre diese Ausgabe in der vorliegenden Gestalt nicht möglich gewesen. Auch Isabelle Lüke sei herzlich gedankt für die Transkription der Nachschrift Bluhme sowie Carolyn Iselt und Henri Vogel für die umfangreichen Korrekturarbeiten. Außerdem möchte ich ausdrücklich dem TELOTA-Team der BBAW danken: Stefan Dumont, Martin Fechner, Nadine Arndt, Frederike Neuber und Lou Klappenbach haben die Herstellung dieser Hybridausgabe, die Transkriptionsarbeit, die textkritische Bearbeitung und Referenzierung der Dokumente aufgrund des digitalen Editionsframeworks „ediarum" begleitet und durch hilfreiche Anregungen unterstützt. Schließlich möchte ich dem Archiv der BBAW und den anderen Institutionen danken, die die Publikationserlaubnis für die in diesem Band enthaltenen Quellen und Abbildungen erteilt haben.

Berlin, im Juni 2020

Holden Kelm

\footnotetext{
150 Die digitale Edition wird drei Jahre nach der Druckausgabe auf der Editionsplattform „schleiermacher digital" erscheinen. URL: https://schleiermacher-digital.de (abgerufen 23.06.2020).
} 
